\title{
Weathering of rock to regolith: The activity of deep roots in bedrock fractures
}

Elizabeth A. Hasenmueller ${ }^{\mathrm{a},}$, Xin Gu ${ }^{\mathrm{b}}$, Julie N. Weitzman ${ }^{\mathrm{c}, \dagger}$, Thomas S. Adams ${ }^{\mathrm{c}}$, Gary E. Stinchcomb $^{d}$, David M. Eissenstat ${ }^{c}$, Patrick J. Drohan ${ }^{c}$, Susan L. Brantley ${ }^{\text {bee }}$, Jason P. Kaye

a. Department of Earth \& Atmospheric Sciences, Saint Louis University, Saint Louis, MO, USA

b. Department of Geosciences, The Pennsylvania State University, State College, PA, USA

c. Department of Ecosystem Science and Management, The Pennsylvania State University, State College, PA, USA

d. Watershed Studies Institute and Department of Geosciences, Murray State University, Murray, KY, USA

e. Earth and Environmental Systems Institute, The Pennsylvania State University, State College, PA, USA

*Corresponding author; E-mail: hasenmuellerea@slu.edu; Phone: 1-314-977-7518; Fax: 1$314-977-3117$

$\uparrow$ Current affiliation: Cary Institute of Ecosystem Studies, Millbrook, NY, USA \& City University of New York, Advanced Science Research Center, New York, NY, USA 


\section{ABSTRACT}

Many areas in the world are characterized by shallow soils underlain by weathered bedrock, but root-rock interactions and their implications for regolith weathering are poorly understood. To test the role of tree roots in weathering bedrock, we excavated four pits along a catena in a shale-dominated catchment at the Susquehanna Shale Hills Critical Zone Observatory (SSHCZO), USA. We measured a variety of biological, physical, and chemical properties including: 1) root density, distribution, and respiration, 2) soil gas, and 3) elemental compositions, mineralogy, and morphology of soil, rock, and rock fracture fill at ridge top, midslope, toe-slope, and valley floor sites. As expected, root density declined rapidly with depth; nevertheless, fine roots were present in rock fractures even in the deepest, least weathered rock sampled ( 180 cm below the land surface). Root densities in shale fractures were comparable between the ridge top and mid-slope pits, but were significantly lower in the toe-slope, despite increasing rock fracture densities, which is likely due to a shallower water table depth at the downslope site. Average root respiration (per gram dry weight of root) in rock fractures was comparable to those in the soil. Thus, the total flux of $\mathrm{CO}_{2}$ from root respiration tracked root length density, decreasing with depth. Potential microbial respiration in the soils, estimated as the laboratory $\mathrm{C}$ mineralization potential, was about an order of magnitude lower than measured root respiration in shale fractures. Roots were only observed in large aperture $(>50 \mu \mathrm{m})$ shale fractures that were filled with particulate material. The fill in these fractures was mineralogically and geochemically similar to the lowest soil horizons with respect to clay composition, element mobility, extractable DOC, and potentially mineralizable $\mathrm{C}$ and $\mathrm{N}$, while total $\mathrm{C}$ and total $\mathrm{N}$ values for the fracture fill were similar to the shale bedrock. In the bulk soil, depletion profiles (Al, $\mathrm{Fe}, \mathrm{K}, \mathrm{Mg}$, and $\mathrm{Si}$ ) relative to unweathered shale reflected characteristic weathering of illite 
and vermiculized chlorite to kaolinite and are similar between soils and fracture fill. Such similarities indicate that the fracture coatings are likely the result of pedogenic processes that occur at depth in the fractures rather than translocation of soil particles downward into the fractures. Overall, our data suggest that roots and fill in shale fractures down to $\sim 180 \mathrm{~cm}$ are qualitatively similar to those in surface soil horizons. Thus, the deepest manifestation of the chemical depletion profiles observed in the pits consists of the rock fracture fill, and this fill is present at low concentrations with similarly low concentrations of fine roots. 


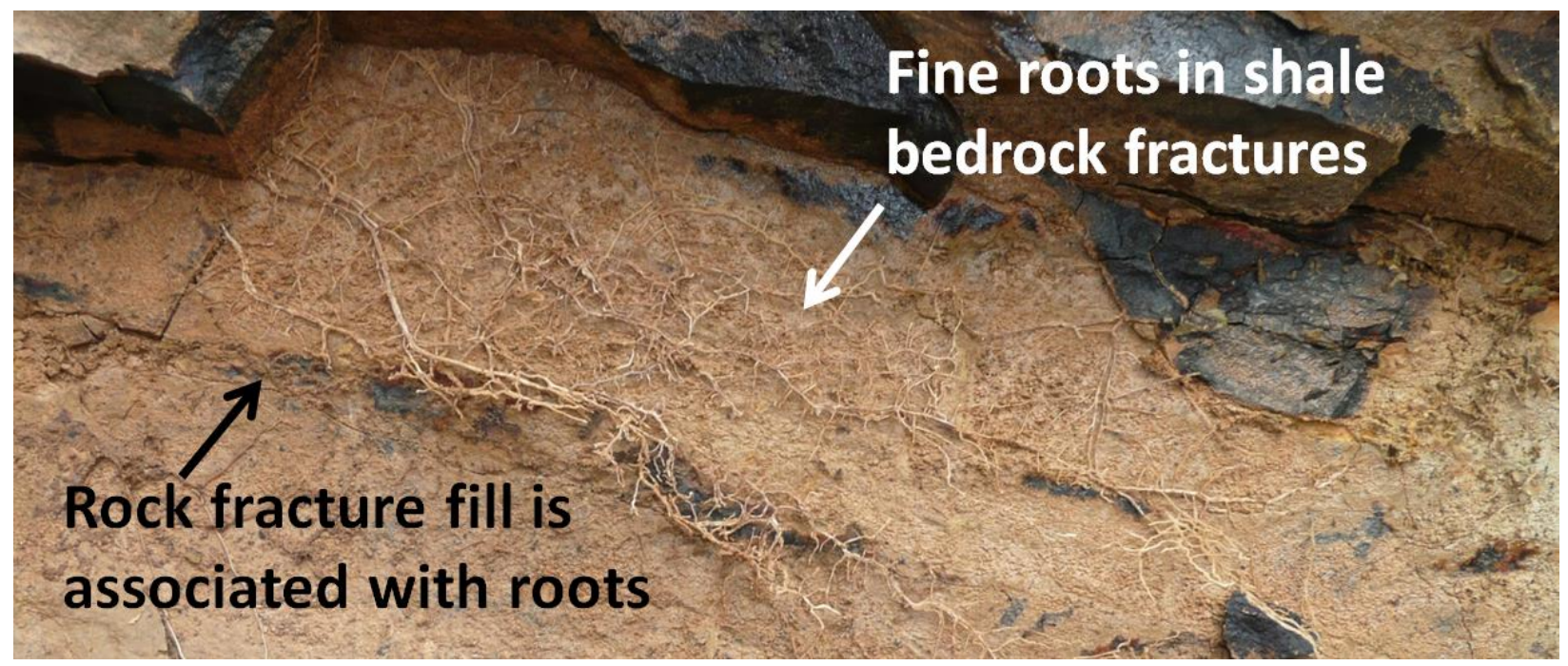

KEYWORDS: rooting depth; vertical root distribution; bedrock weathering; regolith; rock fractures; shale 


\section{INTRODUCTION}

Plants play a key role in weathering regolith in the critical zone, but this role varies as a function of water use, rooting depth and distribution, and associated mycorrhizal fungi (Reneau and Dietrich, 1991; Van Breemen et al., 2000; Balogh-Brunstad et al., 2008; Fimmen et al., 2008; Graham et al., 2010; Schulz et al., 2016). Of particular importance are the mineral weathering reactions that consume $\mathrm{CO}_{2}$ and organic acids produced by plant roots and soil microorganisms (Leake et al., 2008; Ahmed and Holmström, 2015). Such weathering processes exert important controls on global $\mathrm{C}$ cycles and climate change over geological timescales. Interactions between physical, chemical, and biological processes transform bedrock into soil and provide inorganic nutrients to terrestrial biota. When bedrock is physically and chemically weathered, it enhances rock porosity, which is crucial for changing biologically inert rock into materials from which plants and microorganisms can extract water and nutrients (Brantley, 2010; Wald et al., 2013). For example, as early as 1840, Jackson (1840) found that the expansion of biotite due to oxidation may further enhance fracture propagation and the degradation of rock to regolith. Plant roots can also promote these chemical and physical weathering processes and alter the morphology of the bedrock (Graham et al., 1994; Frazier and Graham, 2000; Schenk and Jackson, 2005; Graham et al., 2010).

The weathering potential of tree roots depends, in part, on rooting depth. Rooting depth is a direct function of climate, particularly annual precipitation and potential evapotranspiration (Schenk and Jackson, 2002a,b), species (Gale and Grigal, 1987), soil thickness (Stone and Kalisz, 1991; Anderson et al., 1995; Sternberg et al., 1996; Hubbert et al., 2001a,b; Witty et al., 2003; Bornyasz et al., 2005; Graham et al., 2010), inherent and dynamic soil properties (Kochenderfer, 1973; Nicoll et al., 2006), and bedrock properties (Witty et al., 2003). Plant roots 
are predominantly located in the upper portions of the soil profile, and Schenk and Jackson (2005) found that on a global scale around half of all roots are located in the top $30 \mathrm{~cm}$ of soil and $95 \%$ are in the top $2 \mathrm{~m}$. Vertical rooting depth is generally assumed to be limited in shallow soils because root growth is restricted by the solid bedrock below, and thus most studies of root dynamics are confined to the uppermost soil horizons. Nevertheless, many landscapes are characterized by shallow soils that are underlain by actively weathering bedrock containing fractures that can allow soil, gases, water, and roots to move downward. Roots have been observed to penetrate many meters into bedrock along joints and fracture planes, particularly in upland areas (Hellmers et al., 1955; Scholl, 1976; Stone and Kalisz, 1991; Anderson et al., 1995; Canadell and Zedler, 1995; Jackson et al., 1999; Hubbert et al., 2001a,b; Egerton-Warburton et al., 2003; Rose et al., 2003; Witty et al., 2003; Bornyasz et al., 2005; Graham et al., 2010; Estrada-Medina et al., 2013). Despite the common observance of roots in rock fractures, rarely has the rooting environment within fractures been explored, partially due to the difficulties and expense of excavating solid rock (Maeght et al., 2013).

Studies of the distribution of deep roots in rocks are largely restricted to arid and droughtprone environments where deep roots allow woody vegetation to access water from below the soil in weathered bedrock reserves (Lewis and Burgy, 1964; Zwieniecki and Newton, 1995; Hubbert et al., 2001a,b; Egerton-Warburton et al., 2003; Rose et al., 2003; Witty et al., 2003; Bornyasz et al., 2005; Schenk, 2008; Duniway et al., 2010; Graham et al., 2010; Schwinning, 2010). The majority of these studies focus on the water-holding capacity of weathered rocks, but they rarely address the physical and biogeochemical dynamics of this environment. Moreover, in temperate regions with higher rainfall, trees do not experience the same water limitations as arid environments. Indeed, Gaines et al. (2015) found that the isotopic signature of stem water in 
central Pennsylvania forests showed that trees mainly obtained their water from the upper soil horizons. Thus, the advantages of deep roots in humid environments are less clear. Additionally, studies of deeply rooted systems have investigated only a few lithologies including limestone (Hasselquist et al., 2010; Estrada-Medina et al., 2013) and granite (Hubbert et al., 2001a,b; Witty et al., 2003; Bornyasz et al., 2005; Graham et al., 2010; Poot et al., 2012).

We investigated the abundance and activity of roots in shale bedrock fractures, characterized the growing environment of the roots within the fractures by examining the adjacent materials and porefluid chemistry, and assessed the potential of roots in rock fractures to promote rock weathering along a catena in a forested catchment in the northern Appalachian Mountains (i.e., a catchment close to the Shale Hills experimental watershed in the Susquehanna Shale Hills Critical Zone Observatory; SSHCZO) where the climate is temperate and humid. Assessing the role of deep roots in rock will lead to a better understanding of controls on rooting depth and hillslope regolith development.

\section{MATERIAL AND METHODS}

\subsection{Site description}

Our study area, Missed Grouse Gulch, is a temperate, forested watershed located in the Appalachian Valley and Ridge Province of central Pennsylvania. The site is just two valleys $(\sim 0.25 \mathrm{~km})$ north of the Shale Hills experimental watershed in the SSHCZO (Fig. 1). We selected the Missed Grouse Gulch site to study deep root activity because it features lithology, soils, and vegetation similar to the well-studied Shale Hills catchment and is easily accessed by excavation equipment. We could not excavate at Shale Hills due to the risk of disturbing ongoing experiments. Furthermore, the Missed Grouse Gulch watershed is immediately next to three en 
echelon catchments (including Shale Hills) that have been previously studied and shown to have identical geology and geomorphological evolution (West et al., 2014). The Missed Grouse Gulch watershed is 48 ha, with a valley and perennial stream that roughly align east-west near the outlet and northeast-southwest near the headwaters. The mean annual air temperature is $10^{\circ} \mathrm{C}$, but varies between a minimum of $-28^{\circ} \mathrm{C}$ and maximum of $39^{\circ} \mathrm{C}$, while annual precipitation is $99 \mathrm{~cm}$, with the highest rainfall months occurring in the spring (period of record is 1931-2015; NOAA, 2016). The Missed Grouse Gulch catchment is covered by mostly deciduous trees including oaks (Quercus spp.), maples (Acer spp.), and hickories (Carya spp.), while conifers are less abundant and include Eastern hemlocks (Tsuga canadensis) and pines (Pinus spp.). The excavated catena lies along a north (i.e., south-facing) planar hillslope that is convex-upward near the ridge and concave-upward near the valley floor. The catena is defined as "planar" following Jin et al. (2010) because it does not experience convergent flow of water and sediments; rather, the flow is strictly vertical (one-dimensional) or directly downslope (two-dimensional).

The entire basin is underlain by Silurian Rose Hill Formation shale (Berg et al., 1980), which consists of quartz, illite, chlorite, "vermiculitized" chlorite (i.e., chlorite interlayered with vermiculite), Fe-oxides, minor feldspar, and, at depth, variable amounts of Fe-Mn-Ca carbonates (Jin et al., 2010; Brantley et al., 2013; Sullivan et al., 2016). We follow Jin et al. (2010) and use "chlorite" to refer to true chlorite, vermiculitized chlorite, and hydroxy-interlayered vermiculite. Important geochemical reactions involved in weathering shale to soil have been mapped across the Shale Hills watershed (Jin et al., 2010; Andrews et al., 2011; Jin and Brantley, 2011; Jin et al., 2011a; Ma et al., 2011a,b; Yesavage et al., 2012; Brantley et al., 2013). Just beneath the depth of refusal to hand augering, illite and chlorite begin to weather significantly, and we surmise these reactions lead to, or are driven by, disaggregation of the bedrock (Jin et al., 
2011b). In this paper, we use the term "bedrock" to refer to material directly underlying regolith that was impossible to dig using a trackhoe, as described in Section 2.2. We also note that what we refer to here as "bedrock" has been termed "saprock" in Jin and Brantley (2011) because it has been chemically altered to a very small extent. Specifically, $\mathrm{Fe}^{2+}$ and carbonate minerals have been depleted. In addition, throughout Shale Hills, the uppermost 5 to $8 \mathrm{~m}$ of rock underlying the soil has been heavily fractured, a phenomenon attributed to periglacial conditions during the Last Glacial Maximum (Jin et al., 2010; Kuntz et al., 2011; Jin and Brantley, 2011; Brantley et al., 2013).

Soil thickness at Shale Hills (which has been previously defined as the depth of the material that can be hand-augered) varies from $<20 \mathrm{~cm}$ on the ridges to $>2.5 \mathrm{~m}$ in the valley. Unlike the shale parent material, soils contain insignificant amounts of carbonate and larger amounts of vermiculitized chlorite and illite minerals, which weather to vermiculite, hydroxyinterlayer vermiculite, Fe-oxides, and minor amounts of kaolinite (Jin et al., 2010; Ma et al., 2011a; Jin and Brantley, 2011). Detailed soil descriptions from our sampling sites in Missed Grouse Gulch can be found in Tables S1-S4. Additional information on soil properties for similar soils in the proximal Shale Hills catchment can be found in Lin (2006) and Jin et al. (2010).

Regolith formation rates measured at the ridge tops on both sides of the Shale Hills catchment are equal to $40 \pm 22$ to $45 \pm 12 \mathrm{~m} \mathrm{My}^{-1}$ based on U-series isotopes (Ma et al., 2010; Ma et al., 2013), while the rates of erosion at these positions are only $16.1 \pm 5.6$ to $19.4 \pm 6.2 \mathrm{~m} \mathrm{My}^{-1}$ based on ${ }^{10} \mathrm{Be}$ measurements (West et al., 2013). This suggests that ridge top soils could be deepening by as much as $26 \mathrm{~m} \mathrm{My}^{-1}$ as the catchment recovers from the periglacial conditions imposed during the Last Glacial Maximum. Based on observations from West et al. (2014) at 
Shale Hills and other nearby catchments, we expect these soil production and erosion rates to be comparable with rates in the Missed Grouse Gulch watershed.

\subsection{Site excavation}

We excavated four pits in September 2013 along a catena (i.e., ridge top, mid-slope, toeslope, and valley floor) in the Missed Grouse Gulch catchment (Fig. 1). We removed regolith down to the Silurian Rose Hill Formation shale bedrock with a trackhoe in the ridge top, midslope, and toe-slope pits; however, we were unable to reach bedrock in the valley floor pit because the regolith depth exceeded the length of the trackhoe arm (i.e., $>220 \mathrm{~cm}$; Fig. 2A-D). In the pits where we could reach the bedrock, we were able to excavate the shale to depths of 150$175 \mathrm{~cm}$ below the organic soil surface with an electric jackhammer. Greater depths were not attainable due to compromised pit stability and excavation equipment limitations. The width and length of pits ranged from 150-350 cm (Fig. 2A-C), depending on stability. The bedrock strikes ranged from $\mathrm{N} 50^{\circ} \mathrm{E}$ to $\mathrm{N} 70^{\circ} \mathrm{E}$ and dips ranged from $46^{\circ} \mathrm{NW}$ to $84^{\circ} \mathrm{NW}$ in the three pits, which correspond to those observed at the Shale Hills catchment (Jin et al., 2010; West et al., 2013; Sullivan et al., 2016). We aligned the pits so that two walls were parallel and two walls were perpendicular to the bedding plane of the shale. This strategy maximized our ability to map roots preferentially growing between bedding plane fractures in three dimensions. All pits were excavated within $48 \mathrm{~h}$ of each other to minimize variations in the amount of time that roots were exposure to ambient conditions. After digging, the pit walls were cleaned with a trowel to obtain a smooth surface to photograph root and rock fracture distributions and to collect samples for geochemical analyses. Five to seven reference markers were placed every $\sim 60 \mathrm{~cm}$ along the pit walls to use for grid reference lines during scaled mapping of root and rock fracture densities and 
to mark designated replicate sample locations for root and geochemical sampling. We then identified soil horizons in the field for each pit (Tables S1-S4).

\subsection{Root respiration and root length density mapping}

Once a pit was excavated, plant roots were immediately extracted from three depth intervals within the soil, which roughly correlated to A, B, and C soil horizons, and two depths below the soil in shale bedrock fractures at each of the replicate sample locations (i.e., five replicate sampling profiles at the valley floor and seven replicate sampling profiles for all other catena positions). At the valley floor all five samples at a given replicate sample location were collected in the soil. We did not identify root species, but we did map tree species within a 10-m radius of each sampling site to help qualitatively assess the species of roots collected from the pits. Given the limited amount of undergrowth in the forest, the majority of the root samples from the pits were tree roots. We also avoided sampling herbaceous roots based on root thickness, branching morphology, and root color. Fine root samples $\left(1^{\text {st }}\right.$ to $3^{\text {rd }}$ order roots, where $1^{\text {st }}$ order is the most distal branch; Fig. 2E-J) were excised from higher order woody roots on the pit walls, rinsed with deionized water to remove any attached particles, and measured for respiration using the methods of Walker (1987). In detail, the roots were placed in chambers in 2-(N-Morpholino)ethanesulfonic acid (MES)-buffer solution using a Clark-type oxygen electrode (Hansatech Oxygraph, King's Lynn, United Kingdom). The respiration of all roots was measured within $1 \mathrm{~h}$ of collection and all of the root samples were kept moist prior to measurement. The temperature in the root respiration chambers was regulated by circulating water stored in a $20 \mathrm{~L}$ cooler. This procedure proved inadequate, however, as the temperature of the respiration systems increased over the course of the day. The resulting respiration measurements were temperature-corrected using a temperature response curve with $\mathrm{Q}_{10}=2(\mathrm{a}$ 
curve in which the rate of respiration doubles for each $10^{\circ} \mathrm{C}$ increase in temperature), a temperature response commonly reported in temperate forests (Burton et al., 2008). Following measurement of respiration, roots were oven-dried at $60^{\circ} \mathrm{C}$ for $24 \mathrm{~h}$ and weighed to obtain dry mass. This dry mass was then used to normalize the root respiration and we report data in units of nmol $\mathrm{CO}_{2} \mathrm{~s}^{-1} \mathrm{~g}^{-1}$. We assumed a respiratory quotient of 1 to convert root consumption of $\mathrm{O}_{2}$ to $\mathrm{CO}_{2}$ evolution (Bloom et al., 1992).

After tree root samples were collected, we photographed (Panasonic Lumix DMC-TZ3; 7.2 megapixel; Osaka, Japan) two perpendicular walls of each pit to assess root length density and distribution using profile wall mapping methods similar to those of Dauer et al. (2009). Photographs were taken along portions of the pit faces that had not been disturbed by root sampling. A metric tape measure or pre-measured $10 \times 10 \mathrm{~cm}$ frame was used as a scale reference in the photographs and as a guide to move the camera in depth increments of $10 \mathrm{~cm}$ along the pit walls. An image series as a function of depth was collected at each replicate site for every pit. The images were then processed using Photoshop software to mark and count the number of root intersections (i.e., cross sections) per image area. Root intersections per unit area, calculated in units of root intersections per $100 \mathrm{~cm}^{2}$, are directly proportional to root length density, assuming roots are randomly oriented (Escamilla et al., 1991).

To evaluate the accuracy of our photographic method for determining root length densities based on profile-wall mapping, plant roots were also collected from push core samples that were manually hammered vertically through the soil profile to refusal. At each catena location, four replicate cores were collected within $50 \mathrm{~cm}$ of the pit using $5.1-\mathrm{cm}$ diameter coring equipment (Giddings Machine Company, Inc., Windsor, Colorado). The resulting cores were sectioned into 10-20 cm depth increments and the roots from each depth increment were cleaned 
of soil with water and scanned on an Epson Perfection 4900 desktop scanner. Only tree roots were included in the scans, and we avoided herbaceous species based on color and morphology. Root length was determined from the scanned images using WinRhizo software (Regent Instruments, Quebec City, Quebec, Canada). After scanning, the roots were oven-dried at $60^{\circ} \mathrm{C}$ for $24 \mathrm{~h}$ and weighed to obtain dry mass. Below the depth of refusal by hand augering, however, we were unable to collect similar core samples.

We estimated total $\mathrm{CO}_{2}$ production by root respiration $\left(\mathrm{nmol} \mathrm{CO}_{2} \mathrm{~cm}^{-3} \mathrm{~s}^{-1}\right)$ as a function of depth in the soil and rock fractures using both our respiration and root density data. In soil, we used root core data (mass of dry weight root tissue per unit soil volume) and average root respiration (nmol $\left.\mathrm{CO}_{2} \mathrm{~g}^{-1} \mathrm{~s}^{-1}\right)$ to determine total $\mathrm{CO}_{2}$ production per unit volume soil for a given soil layer. In the rock, where we did not have known root densities per volume, we calculated total $\mathrm{CO}_{2}$ production rates per unit volume rock by correlating root mass per volume of soil in the regolith (from our cores) to intersections photographed on the pit face for the same depth in the soil $\left(\mathrm{R}^{2}>0.63\right)$. We extrapolated these mass to intersection relationships for roots in bedrock fractures where we only had intersection data from photographs. Respiration for each $10 \mathrm{~cm}$ layer was multiplied by the actual (i.e., soil) or estimated (i.e., rock) root mass per volume in that layer to approximate $\mathrm{CO}_{2}$ contributions rates per unit volume of solid material by plant roots.

\subsection{Soil gas sampling}

From August to December 2013, we characterized soil gas fluxes and concentrations at undisturbed sites near the pits to understand the role of root respiration in overall soil gas dynamics. To measure soil surface $\mathrm{CO}_{2}$ flux, we installed four replicate 5.1-cm diameter soil collars near each pit site (all replicate locations were within $200 \mathrm{~cm}$ of each other and the pit). We connected a PVC adapter to the soil collar that was then attached to a soil respiration 
chamber (SRC-1 PP-systems; Hitchin, United Kingdom) on a handheld infrared gas analyzer (IRGA; EGM-4, PP-systems, Hitchin, United Kingdom) to measure soil surface $\mathrm{CO}_{2}$ flux.

Soil gas at varying depths (ranging from 10-70 cm) was also measured for soil $\mathrm{CO}_{2}$ and $\mathrm{O}_{2}$ concentrations (i.e., $\mathrm{pCO}_{2}$ and $\mathrm{pO}_{2}$, respectively) along the catena. We monitored $\mathrm{pCO}_{2}$ and $\mathrm{pO}_{2}$ by installing nested gas samplers at each site following the methods of Hasenmueller et al. (2015). Briefly, vertical soil gas samplers were placed in hand-augered holes to the desired depth within $200 \mathrm{~cm}$ of each other and the pit at each site. Samplers were generally placed at depth increments of $20 \mathrm{~cm}$ until reaching the depth of refusal by hand augering, but in thin soils and near the soil surface, $10-\mathrm{cm}$ intervals were used to measure gas variation at or near soil horizons. We also measured atmospheric $\mathrm{pCO}_{2}$ and $\mathrm{pO}_{2}$ at a height $<2 \mathrm{~cm}$ above leaf litter during every gas sampling event. We collected data from the soil gas samplers at least weekly between 10:00 and 15:00.

Soil $\mathrm{pO}_{2}$ was measured in situ by connecting a Quantek Instruments model 901 Oxygen analyzer (Grafton, Massachusetts) directly to the soil gas sampler. Instrument accuracy is $\pm 0.2 \%$ of the sample value (see Table S5). Samples for laboratory $\mathrm{pCO}_{2}$ analyses were obtained by connecting a 60 -mL gas-tight syringe to the soil gas sampler and collecting $\sim 30 \mathrm{~mL}$ of soil gas. The gas samples collected for $\mathrm{pCO}_{2}$ determination were immediately transferred from syringes by needle injection to pre-evacuated 15 -mL Labco ${ }^{\circledR}$ glass vials for longer storage before laboratory processing. The Labco® vials were overpressurized with soil gas to prevent contamination during storage. Sample $\mathrm{CO}_{2}$ concentrations were analyzed in the laboratory with an infrared gas analyzer (LI-7000 IRGA; LI-COR Inc., Lincoln, Nebraska) using methods outlined in Hasenmueller et al. (2015). Instrument accuracy is $\pm 1 \%$ of the sample value (LICOR, 2007). 


\subsection{Rock fracture mapping}

Fracture densities in the shale bedrock were quantified utilizing the same photographs of the vertical pit faces that were used for the root density and distribution mapping. Fracture mapping methods were modified after Paul et al. (2010). In detail, rock fracture length and width were calculated in Adobe Illustrator using the reference scales in the photographs. Fractures were separated into three categories based on aperture: $\leq 250 \mu \mathrm{m}, 250-2000 \mu \mathrm{m}$, and $\geq 2000 \mu \mathrm{m}$. In our classification scheme, the $250-\mu \mathrm{m}$ boundary was selected because it represents the lowest, reliable fracture width we could observe with our photographic technique; it is also the boundary between fine and medium sand. We were able to map hairline fractures down to $\sim 50 \mu \mathrm{m}$, but could not reliably measure the aperture from photographs. Our upper limit of $2000 \mu \mathrm{m}$ was selected because it represents the boundary between soil and rock fragments (i.e., very coarse sand versus gravel). We estimated the volume of fracture void space for each width category in the weathered shale in 10-cm depth intervals at each catena site. In detail, we multiplied the average fracture length on the pit wall parallel to strike, the average fracture length on the pit wall perpendicular to strike, and the fracture category width.

\subsection{Physiochemical measurements}

To assess the environment for roots growing below the augerable regolith as well as the potential for roots to promote rock weathering, samples of soil, shale bedrock, and shale fracture fill were collected from the catena pits at varying depths. In the augerable regolith, we obtained intact core samples by horizontally inserting a $2.54 \mathrm{~cm}$-diameter push corer $20 \mathrm{~cm}$ into each pit face at depth intervals roughly corresponding to those for root collection. In the weathered bedrock, samples for geochemical analysis were removed at two depths from each pit face using a rock hammer. The two shale sampling depths were also approximately the same as the 
locations sampled for roots. Rock fracture fill was collected by scraping material from fracture surfaces using a plastic spatula. The volume of the fracture fill was often limited, and therefore samples were sometimes collected over a larger depth interval (see red asterisk in Fig. 2A) and at a lower frequency than the soil and rock samples. We collected 167 samples total over the field campaign. Each sample was sealed in a plastic bag, stored in a cooler with ice in the field, and later processed upon arrival at the lab on the same day of collection to prepare and/or stabilize samples for laboratory analyses.

Untreated soil samples were weighed to determine bulk density, then both soil and fracture fill samples were homogenized by hand and subsampled for determination of gravimetric water content (referred to as water content hereafter), extractable dissolved organic $\mathrm{C}$ (DOC), potential $\mathrm{C}$ and $\mathrm{N}$ mineralization (i.e., the decomposition or oxidation of organic matter into plant accessible forms), major and trace elemental composition, and mineralogy. A $\sim 10 \mathrm{~g}$ subsample of fresh soil or fracture fill was oven-dried $\left(105^{\circ} \mathrm{C}\right)$ to a constant mass and sieved $(2 \mathrm{~mm})$; we then determined the water content for the dried, $<2 \mathrm{~mm}$ fraction (Gardner and Klute, 1986). The bulk density of intact, unsieved soil core samples was calculated using the oven-dried mass of samples and known core sampler volumes (Blake and Hartge, 1986). To determine the water content of the fractured shale, we weighed untreated shale fragments (generally with masses ranging from 100 to $800 \mathrm{~g}$ ) collected below the augerable regolith and then oven-dried $\left(105^{\circ} \mathrm{C}\right)$ them to a constant mass. To estimate the bulk density of the untreated shale samples, rock volume was measured by determining the displacement volume when weighed shale fragments were submerged in water. We were unable to measure bulk density for the fracture fill due to difficulties determining the samples' original volume.

\subsubsection{Biogeochemical characterization}


A second $\sim 10 \mathrm{~g}$ subsample of fresh soil or fracture fill was immediately extracted using $100 \mathrm{~mL}$ of $2.0 \mathrm{M} \mathrm{KCl}$. A third $\sim 10 \mathrm{~g}$ subsample of the untreated soil or rock fracture fill was placed in a $120-\mathrm{mL}$ glass serum bottle (Wheaton) and sealed with a septum. We then estimated the $\mathrm{C}$ mineralization and net $\mathrm{N}$ mineralization potential by 7-day laboratory incubations at $25^{\circ} \mathrm{C}$ using methods outlined in Binkley and Hart (1989), Hart et al. (1994), and Hart and Stark (1997). Soil moisture conditions during the experiment approximated those in the field at the time of collection. To account for ambient $\mathrm{CO}_{2}$ conditions, serum bottles containing ambient air were also sealed as controls for the 7-day incubation. After 1-2 days we mixed and sampled (1 mL) the headspace of the serum bottles with a syringe to determine the concentration of $\mathrm{CO}_{2}$ using an LI-7000 IRGA employing the same method described in Section 2.4. Once the headspace was sampled, the serum bottles were opened and fanned with ambient air to create a uniform background $\mathrm{CO}_{2}$ concentration. The bottles were subsequently resealed with a new septum. This process was repeated 2-3 times during the incubation. The $\mathrm{C}$ mineralization potential is equivalent to the total $\mathrm{C}$ released over the incubation period divided by the incubation period and the mass of solid material (i.e., $\mathrm{mg} \mathrm{C} \mathrm{kg} \mathrm{solid}{ }^{-1} \mathrm{day}^{-1}$ ). The $\mathrm{C}$ mineralization potential results were also temperature-corrected using a temperature response curve with $\mathrm{Q}_{10}=2$.

After the last headspace sampling event, inorganic N-species were extracted with $2.0 \mathrm{M}$ $\mathrm{KCl}$ for each sample. Both the initial and final extractants were filtered with a \#1 Whatman filter and concentrations ( $\mu \mathrm{g} \mathrm{N} \mathrm{g} \mathrm{solid}{ }^{-1}$ ) of $\mathrm{NH}_{4}{ }^{+}-\mathrm{N}$, determined using the salicylate method (Sims et al., 1995), and $\mathrm{NO}_{3}^{-}-\mathrm{N}+\mathrm{NO}_{2}^{-}-\mathrm{N}$, determined using the $\mathrm{VCl}_{3}$ method (Doane and Horwath, 2003), were measured using colorimetric analysis on a spectrophotometer microplate reader. We assumed $\mathrm{NO}_{2}{ }^{-}-\mathrm{N}$ concentrations were negligible, and thus report results as $\mathrm{NO}_{3}{ }^{-} \mathrm{N}$ concentrations (Doane and Horwath, 2003). The net $\mathrm{N}$ mineralization potential was calculated by 
dividing the $\mathrm{NH}_{4}{ }^{+}-\mathrm{N}$ or $\mathrm{NO}_{3}{ }^{-}-\mathrm{N}+\mathrm{NO}_{2}{ }^{-}-\mathrm{N}$ concentration change by the 7-day incubation time and the mass of the solid sample.

To measure variations in DOC at our sites, untreated subsamples of soil ( $20 \mathrm{~g})$ and fracture fill $(\sim 5 \mathrm{~g})$ were extracted with $20 \mathrm{~mL}$ of deionized water. The extractant was measured on a non-dispersive infrared gas analyzer (NDIR; Shimadzu SSM-5000A and TOC-5000A analyzer; Columbia, Maryland). Total $\mathrm{C}$ and $\mathrm{N}$ concentrations in soil and fracture fill samples were measured by dry combustion elemental analysis (CE Instruments EA 1110 CHNS-O elemental analyzer; Wigan, United Kingdom). In detail, soil, fracture fill, and rock were dried at $105^{\circ} \mathrm{C}$ to a constant mass then ground to pass through a 100 -mesh sieve $(<150 \mu \mathrm{m})$ using a roller-mill grinder (see Weitzman et al., 2014 for details). Between 10-12 mg of ground sample was weighed into a $5 \times 8 \mathrm{~mm}$ tin capsule so that $\mathrm{C}$ and $\mathrm{N}$ concentrations would fall in a range suitable for measurement on the elemental analyzer. After preparing the tin capsules, samples were analyzed via flash combustion $\left(1100^{\circ} \mathrm{C}\right)$ in the elemental analyzer to convert solid $\mathrm{C}$ and $\mathrm{N}$ to simple gases $\left(\mathrm{CO}_{2}\right.$ or $\mathrm{N}_{2}$, respectively; Matejovic, 1997). Instrument standards were used for calibration, and check standards $(\sim 0.9 \mathrm{mg})$ and references $(\sim 10 \mathrm{mg})$ with known $\mathrm{C}$ and $\mathrm{N}$ concentrations were used to ensure that no drift occurred during the run.

\subsubsection{Soil and fracture fill pH, acid neutralizing capacity, and base neutralizing capacity}

Five methods were used to characterize air-dried soil and fracture fill acidity as a function of depth. The $\mathrm{pH}$ was measured in solutions of deionized water, $0.01 \mathrm{M} \mathrm{CaCl}_{2}$, and $1.0 \mathrm{M} \mathrm{KCl}$ with a soil weight to solution volume of 1:1. The empirical methods of Binkley et al. (1989) and Binkley and Sollins (1990) were used to determine the acid neutralizing capacity and base neutralizing capacity for soil and fracture fill. Resource limitations prevented measurement of all 167 original samples, so six composite soil samples for each sampling depth interval (three for 
acid neutralizing capacity and three for base neutralizing capacity) were prepared from air-dried individual samples. Because of the limited amount of fill in the fractures, we only tested acid neutralizing capacity and base neutralizing capacity for one fracture fill sample at the ridge top pit. Solid samples were weighed and placed in $125-\mathrm{mL}$ specimen cups. We then added $1.0 \mathrm{M}$ $\mathrm{KCl}$ to buffer the ionic strength of the slurry. The solid weight to $1.0 \mathrm{M} \mathrm{KCl}$ volume had a ratio of 1:1. For acid neutralizing capacity, we then made consecutive additions of $0.2-0.5 \mathrm{~mL}$ of 0.01 $1.0 \mathrm{M} \mathrm{HCl}$, depending on buffering capacity, and measured the $\mathrm{pH}$ of the solution after $24 \mathrm{~h}$ on a shaker. Additions were stopped after a $\mathrm{pH}$ of 3.0 was reached. For base neutralizing capacity, the second set of subsamples received additions of $0.2-0.5 \mathrm{~mL}$ of $0.01-1.0 \mathrm{M} \mathrm{NaOH}$; additions of $\mathrm{NaOH}$ were stopped after a $\mathrm{pH}$ of 8.2 was reached.

\subsubsection{Elemental and mineral analyses}

We analyzed bulk (i.e., samples that were not sieved to separate grain sizes) soils, fracture fill, and shale bedrock samples for major elements. Samples were air-dried, ground to pass through a 100-mesh sieve $(150 \mu \mathrm{m})$, prepared with a $\mathrm{LiBO}_{2}$ fusion (Feldman, 1983), and analyzed using inductively coupled plasma atomic emission spectroscopy (ICP-AES; PerkinElmer Optima 5300DV ICP-AES, Waltham, Massachusetts; precision is $\pm 3 \%$ for the major elements; Brantley et al., 2013). We determined element ratios by calculating $\tau$ values using elemental data (see Table 1) from ICP-AES analyses. The $\tau$ value is defined as:

$$
\tau_{i, j}=\frac{c_{j, w} c_{i, p}}{C_{j, p} c_{i, w}}-1
$$

where $j$ is a mobile element, $i$ is an immobile element, $w$ is the concentration of the element in the sample of interest, and $p$ is the concentration of the element in the parent material (Brimhall and Dietrich, 1987; Anderson et al., 2002). For our study, elemental abundances in the parent material were averaged from samples collected from two deep boreholes drilled along the ridges 
of the Shale Hills watershed (samples DC1 and DC9; see Sullivan et al., 2016). As shown by Jin et al. (2010), soils in Shale Hills lose material due to both solubilization and micron-sized particle loss. Depending on the choice of immobile element, $\tau$ values can reveal the extent of depletion with respect to the parent material due to either of those mechanisms. Specifically, $\mathrm{Zr}$ is only present in zircons in Silurian Rose Hill Formation shale (Jin et al., 2010), and zircons are highly resistant to chemical weathering and physical movement (due to their chemical resistance, high density, and large grain size). As a result, if we choose $\mathrm{Zr}$ as an immobile element, a negative $\tau$ value between -1 and zero represents elemental losses due to both solutes and particles. On the other hand, the concentration of $\mathrm{Al}$ is extremely low in soil porewater (Jin et al., 2014) and stream water (Jin et al., 2014; Sullivan et al., 2016) in the nearby Shale Hills catchment, and it is reasonable to assume $\mathrm{Al}$ is only lost as micron-sized or smaller particles. Therefore, if we use $\mathrm{Al}$ as the immobile element to calculate $\tau$, a negative $\tau$ value represents the extent of elemental loss strictly as solutes (Sullivan et al., 2016).

X-ray diffraction (XRD) analysis of the soils, fracture fill, and shale was performed on air-dried, powdered samples $(<150 \mu \mathrm{m})$ with a PANalytical Empryean X-Ray Diffractometer (PANalytical Ltd., The Netherlands) at $45 \mathrm{kV}$ and $40 \mathrm{~mA}$ with a $\mathrm{Cu} \mathrm{K} \alpha$ radiation. Stepwise scanning measurements were performed at a rate of $4^{\circ} \min ^{-1}$ in the range of $5-70^{\circ} 2 \theta$. The relative mineral percentages were estimated semi-quantitatively by Rietveld analyses using the Jade software.

\subsubsection{Thin section analyses}

The micromorphology of a weathered rock thin section was examined to determine the presence or absence and nature of materials filling fractures. Weathered shale containing fractures and roots was collected from $35 \mathrm{~cm}$ deep at the ridge top pit with the orientation 
preserved and shipped to Spectrum Petrographics, Inc. (Vancouver, Washington) for thin section fabrication. Thin sections of weathered rock with fractures and roots were not made for the other sampling sites because of the difficulty of preserving oriented weathered rock during sample extraction. The resulting thin section from the ridge top profile was described qualitatively using a Zeiss Primotech (Jena, Germany) polarizing light microscope using standard techniques (Stoops, 2003).

\subsubsection{Shale nanoporosity by neutron scattering}

Small-angle neutron scattering (SANS), combined with ultra small-angle neutron scattering (USANS), was used to qualitatively analyze the pore structure in shale chips (from pits where we were able to reach bedrock) and their relationship to weathering by root action. Neutrons scatter mainly from the pore-grain interface and are able to probe pores of nominal sizes from $1 \mathrm{~nm}$ to several $\mu \mathrm{m}$. This technique has been used to characterize the change of pore structure during shale weathering in the nearby Shale Hills catchment (Jin et al., 2011b). In this study, we strategically measured shale chip (approximately $1-3 \mathrm{~cm}$ in size) porosity around rooting and non-rooting zones to determine whether rooting depth and distribution influence shale porosity. The neutron scattering measurements were carried out at the NIST Center for Neutron Research (NCNR), Gaithersburg, MD, using NG3 beamline for SANS and BT5 for USANS. Both SANS and USANS measurements were performed on thin sections of the small shale chips (around $150 \mu \mathrm{m}$ thickness, cut parallel to bedding, and double polished). Details of the experimental method, data reduction, and interpretation are described by Jin et al. (2011b).

\subsubsection{Rock-rock interface imaging}

We imaged roots, soils, and shale fracture surfaces (Fig. 2H-J) using a scanning electron microscope (SEM) on untreated samples. An FEI Nova NanoSEM 630 (Hillsboro, Oregon) with 
an accelerating voltage of $8-10 \mathrm{kV}$, landing energy in the range of $2-3.5 \mathrm{kV}$, spot size of 4 , and working distance of $5 \mathrm{~mm}$ was used for analyses. The images were taken under backscattered electron (BSE) mode using a vCD detector. Energy dispersive x-ray spectra (EDS) were acquired on the SEM using an Oxford EDS detector.

\section{RESULTS}

\subsection{Bedrock fracture densities}

Fractures in the vertical pit faces imaged by our photography were predominantly oriented along, or parallel to, bedding, but could be found in any orientation (Fig. 2A-C). In all three pits where we reached bedrock, we observed large vertical fractures that were generally oriented perpendicular to bedding (see asterisk in Fig. 2A for an example). These vertical fractures were often the widest fractures observed in the pits (typically $>0.5 \mathrm{~cm}$ ) and often had high root densities and secondary mineral content. Overall shale fracture densities were highest (lengths totaling up to $175 \mathrm{~cm}$ per $100 \mathrm{~cm}^{2}$ ) just below the augerable regolith (i.e., $40-50 \mathrm{~cm}$ for ridge top, 70-90 cm for mid-slope, and 90-110 cm for toe-slope), then decreased with increasing depth into the bedrock. For the ridge top, mid-slope, and toe-slope profiles (Fig. 3A), these length densities correlated to fracture volumes (i.e., percent of the total rock volume occupied by fractures) just below the soil-rock interface of $6.3 \pm 1.7$ vol. $\%, 6.0 \pm 1.6$ vol. $\%$, and $7.4 \pm 2.1$ vol. $\%$, respectively, and to the lowest observed volumes of $1.1 \pm 0.9$ vol. $\%, 0.9 \pm 0.7$ vol. $\%$, and $2.0 \pm 1.4$ vol. $\%$, respectively, in the deepest part of the pits (Fig. 3B). The toe-slope had the highest rock fracture volume $(p=0.03)$, but there was no significant difference between the ridge top and mid-slope $(p=0.82)$. From field, photographic, and thin section (see Section 3.7) 
observations, we found that high fracture volume was associated with higher fill material content in the fractures.

\subsection{Root distribution}

Tree species assemblages within a 10-m radius of the ridge top (7\% white oak, $7 \%$ sugar maple, and $86 \%$ white pine; $n=14)$, mid-slope ( $60 \%$ red oak, $30 \%$ sugar maple, and $10 \%$ white pine; $n=10)$, toe-slope (17\% sugar maple and $83 \%$ white pine; $n=6)$, and valley floor $(20 \%$ white oak, 40\% sugar maple, 33\% Eastern hemlock, and 7\% white pine; $n=15$ ) pits were qualitative indicators of the type of roots observed in each pit. These data suggest that the ridge top and toe-slope pits were likely dominated by conifer roots. In contrast, the mid-slope and valley floor pits were likely more influenced by deciduous tree roots.

For all the catena positions, using either the coring (measured as root length per volume of soil; Fig. 3C) or profile-wall mapping (measured as intersections per $100 \mathrm{~cm}^{2}$; Fig. 3D) methods, root length densities decreased significantly with depth $(p<0.01)$. Roots were most abundant in the upper soil and decreased by two orders of magnitude at the bottom of the pits. Nevertheless, fine roots were observed in shale fractures at all the sites where we reached bedrock. Qualitatively, we observed that roots in the rock fractures tended to be finer and flattened compared to those located in the overlying soil where they were not confined and generally remained rounded in shape. Root density did not vary significantly among topographic positions $(p=0.06)$ when all depths were considered. We also examined differences in root abundance as a function of substrate (i.e., soil vs. rock) and topographic position and found that there were no differences in root density among catena sites for the soil $(p>0.76)$ using either method. However, using the profile wall method, we found that the toe-slope had significantly lower root densities $(p<0.01)$ in the bedrock fractures than the upland sites, where the upland 
positions had more than 10-fold higher root densities. There was no difference in root abundance in shale fractures between the ridge top and mid-slope $(p=0.28)$. We also observed that below $40 \mathrm{~cm}$ depth, there were significantly lower $(p<0.01)$ root densities in the toe-slope and valley floor pits compared to the ridge top and mid-slope pits, regardless of substrate.

\subsection{Root and soil C dynamics}

\subsubsection{Root respiration}

Root respiration normalized to root mass ranged from almost zero to $635 \mathrm{nmol} \mathrm{CO}_{2} \mathrm{~g}$ dry wt. $^{-1} \mathrm{~s}^{-1}$ (Fig. 3E). Root respiration did not change significantly as a function of depth $(p>0.08)$ for any of the sample sites. Averaged over all depths, respiration of roots at the ridge top was twice that of roots at the other hillslope positions $(p=0.01)$, but there were no significant differences in respiration among the downslope catena positions $(p=0.12)$. As root density decreased with depth, so did the total $\mathrm{CO}_{2}$ produced from root respiration. In detail, we found that contributions to soil $\mathrm{pCO}_{2}$ from woody plant roots ranged from 0.05 to $0.14 \mathrm{nmol} \mathrm{CO}_{2} \mathrm{~cm}$ $\operatorname{solid}^{-3} \mathrm{~s}^{-1}$ in the top $10 \mathrm{~cm}$ of soil, while contributions ranged from zero (in locations with no roots) to $0.02 \mathrm{nmol} \mathrm{CO} \mathrm{cm} \mathrm{solid}^{-3} \mathrm{~s}^{-1}$ in the rock.

\subsubsection{Soil gas}

Soil gas concentrations varied significantly with profile depth and as a function of hillslope position (Fig. 4A-C). Soil $\mathrm{pO}_{2}$ patterns (Fig. 4B) decreased with depth and were the inverse of those for $\mathrm{pCO}_{2}$ (Fig. $4 \mathrm{C}$ ), with soil $\mathrm{pO}_{2}$ decreasing by up to $15,000 \mathrm{ppm}_{\mathrm{v}}$ with depth. The lowest $\mathrm{pO}_{2}$ values were observed in the valley floor profile and increased significantly $(p<$ $0.01)$ in the upslope positions. Soil $\mathrm{pCO}_{2}$ increased with depth at all the sites $(p<0.01)$ and increased downslope toward the valley floor $(p<0.01)$. The average $\mathrm{pCO}_{2}$ for all sampling depths was more than three times higher at the valley floor than the ridge top (Fig. 4C). At the 
ridge top, the $\mathrm{pCO}_{2}$ was highest in August, when temperatures were warmer, then steadily declined through the end of the monitoring period in December (Fig. S1). At the mid-slope and valley floor, $\mathrm{pCO}_{2}$ was highest from mid-October to mid-November (Fig. S1) when we observed rising water levels in the excavated pits and water in the gas samplers (i.e., sometimes during this period we could only extract water rather than soil gas from the deepest samplers). Starting in late November, $\mathrm{pCO}_{2}$ declined at the mid-slope and valley floor as temperatures decreased. Surface $\mathrm{CO}_{2}$ flux was also monitored at the pit sites from August to December and ranged from 0.02-0.69 $\mathrm{g} \mathrm{CO}_{2} \mathrm{~m} \mathrm{soil}^{-2} \mathrm{~h}^{-1}$ (Fig. S2). The $\mathrm{CO}_{2}$ flux at the soil surface decreased with temperature $\left(R^{2}=0.43\right)$, but did not vary significantly among the sampling sites $(p=0.96)$.

\subsubsection{Soil C}

The total $\mathrm{C}$ along the catena ranged from $0.06 \%$ to $4.70 \%$ (Fig. 4D). The highest values were observed at the ridge top profile $(p<0.01)$, which also had the most variable total C as a function of depth. No significant differences were observed between the downslope sites $(p=$ 0.62). Total $\mathrm{C}$ values were highest in the upper $20 \mathrm{~cm}$ of the profile at all the sites, but concentrations decreased with depth $(p<0.01)$, generally by an order of magnitude (Fig. 4D). The total $\mathrm{C}$ in the shale matrix and fracture fill were not significantly different $(p=0.79)$, but the soils had significantly higher total $\mathrm{C}$ than the fracture material $(p=0.02)$. Extractable DOC (range $=0.78-20.18 \mathrm{ppm})$ was also highest at the ridge top $(p<0.01)$ and generally decreased downslope (Fig. 4E). The maximum concentrations in each profile were observed in the top 10 $\mathrm{cm}$ of soil and in the fracture material at the mid-slope $(p=0.01)$. Due to sample volume limitations, we were unable to measure DOC for fracture fill at the ridge top and toe-slope pits.

Potential C mineralization during the 7-day incubation ranged from 0.12 to $20.95 \mathrm{mg} \mathrm{C}$ $\mathrm{kg} \mathrm{solid}^{-1} \mathrm{day}^{-1}$ (Fig. 4F). The highest potential C mineralization for all depths was observed at 
the ridge top $(p<0.01)$, which had more than three times the $\mathrm{C}$ mineralization potential of the downslope sites. There was no significant difference between the other sites $(p=0.90)$. Potential C mineralization generally decreased with depth for the entire catena, but there was no significant difference between the soil and the fill in the rock fractures $(p=0.21)$.

We compared our laboratory measurements of potential $\mathrm{C}$ mineralization rates to root respiration measured in the field to evaluate $\mathrm{CO}_{2}$ contributions to soil and rock from the respiration of soil microbes and roots, respectively. In the field, respiration for individual roots found in the shale fractures was comparable to root respiration in the augerable regolith. Based on our root density data, we estimate that tree roots contribute $0.01-0.14 \mathrm{nmol} \mathrm{CO}_{2} \mathrm{~cm} \mathrm{solid}^{-3} \mathrm{~s}^{-1}$ in the top $20 \mathrm{~cm}$ of soil and $0-0.02 \mathrm{nmol} \mathrm{CO}_{2} \mathrm{~cm} \mathrm{solid}^{-3} \mathrm{~s}^{-1}$ in the shale fractures. The volume percent of fractures in the shale ranged from $\sim 1-7.5$ vol. $\%$ of the total volume of the rock, with the highest volume of fracture space near the augerable regolith. Thus, roots could contribute anywhere from 0-0.002 $\mathrm{nmol} \mathrm{CO}_{2} \mathrm{~cm} \mathrm{solid}^{-3} \mathrm{~s}^{-1}$ in the bedrock fractures. In comparison, our measurements of potential $\mathrm{C}$ mineralization show that contributions of $\mathrm{CO}_{2}$ from microbial activity could (under wet and warm conditions similar to our incubations) range from $\sim 0.007$ nmol CO $2 \mathrm{~cm} \mathrm{solid}^{-3} \mathrm{~s}^{-1}$ in the top $20 \mathrm{~cm}$ of soil to $<0.001 \mathrm{nmol} \mathrm{CO}_{2} \mathrm{~cm} \mathrm{solid}^{-3} \mathrm{~s}^{-1}$ in the shale fractures. This corresponds to microbial contributions of $<0.0001 \mathrm{nmol} \mathrm{CO}_{2} \mathrm{~cm} \mathrm{solid}^{-3} \mathrm{~s}^{-1}$ in the fractures when fracture volumes are considered.

\subsection{Soil $N$ dynamics}

Soil $\mathrm{N}$ data for the catena are summarized in Fig. 5. Total $\mathrm{N}$ ranged from $0.06 \%$ to $0.30 \%$, with the highest $(p<0.01)$ and most variable values for all depths at the ridge top (Fig. 5B). Downslope of the ridge top, total $\mathrm{N}$ was similar between the sites $(p=0.87)$. Like all of the $\mathrm{C}$-species, total $\mathrm{N}$ decreased with depth $(p<0.01)$ and was always twice as high in the top $10 \mathrm{~cm}$ 
of the profile compared to the deepest samples. There was not a significant difference in total $\mathrm{N}$ between the rock matrix and fracture fill $(p=0.69)$, but the soils had significantly higher total $\mathrm{N}$ than the fracture material $(p=0.01)$.

The $\mathrm{NO}_{3}{ }^{-}-\mathrm{N}$ concentrations in the soils and fracture fill were typically low, ranging from zero to $1.37 \mathrm{mg} \mathrm{kg}^{-1}$ (Fig. 5C), with the highest levels along the catena observed in the ridge top profile $(p<0.01)$. There was a significant decrease in $\mathrm{NO}_{3}{ }^{-} \mathrm{N}$ with depth at the ridge top $(p<$ $0.01)$, but there was no significant change with depth at the other sites $(p>0.08)$. In contrast, the $\mathrm{NO}_{3}{ }^{-}-\mathrm{N}$ concentrations in fracture fill at the ridge top and toe-slope sites were, on average, seven times higher than those observed in the overlying soil horizons $\left(0.57 \mathrm{mg} \mathrm{N} \mathrm{kg} \mathrm{solid}^{-1}\right.$ in fractures versus $0.08 \mathrm{mg} \mathrm{N} \mathrm{kg} \mathrm{solid}{ }^{-1}$ in soil; $p<0.01$ ). High $\mathrm{NO}_{3}{ }^{-} \mathrm{N}$ in fractures was not observed for the mid-slope site. Point measurements of the net rate of $\mathrm{NO}_{3}{ }^{-} \mathrm{N}$ accumulation for all the catena positions were very low, ranging from -0.39 to $0.09 \mathrm{mg} \mathrm{N} \mathrm{kg} \mathrm{solid}^{-1}$ day $^{-1}$ (Fig. 5D), where negative values indicate net microbial immobilization of $\mathrm{NO}_{3}{ }^{-} \mathrm{N}$ and positive values indicate net nitrification. The highest values were observed at the ridge top and valley floor. There was no significant change in net rate of $\mathrm{NO}_{3}{ }^{-} \mathrm{N}$ accumulation at the ridge top, toe-slope, and valley floor sites $(p>0.20)$ as a function of depth, but there was a significant decrease with depth for the mid-slope $(p<0.01)$. There were no significant differences between the net rate of $\mathrm{NO}_{3}{ }^{-} \mathrm{N}$ accumulation in the soils and fracture fill $(p=0.10)$.

Like $\mathrm{NO}_{3}{ }^{-}-\mathrm{N}, \mathrm{NH}_{4}{ }^{+}-\mathrm{N}$ was generally low along the catena (range $=0.10-13.70 \mathrm{mg} \mathrm{N} \mathrm{kg}$ solid ${ }^{-1}$; Fig. 5E), with the ridge top site having the highest $\mathrm{NH}_{4}{ }^{+}-\mathrm{N}$ values at all depths $(p=0.03)$. The fracture fill featured higher average $\mathrm{NH}_{4}{ }^{+}-\mathrm{N}$ concentrations than the soil $(2.94 \mathrm{mg} \mathrm{N} \mathrm{kg}$ solid $^{-1}$ and $0.68 \mathrm{mg} \mathrm{N} \mathrm{kg} \mathrm{solid}{ }^{-1}$, respectively; $p<0.01$ ). In the soil, the $\mathrm{NH}_{4}{ }^{+}-\mathrm{N}$ concentrations were highest in the top $20 \mathrm{~cm}$ for all the profiles $(p<0.01)$. The net rate of $\mathrm{NH}_{4}{ }^{+}-\mathrm{N}$ accumulation 
ranged from -0.38 to $0.27 \mathrm{mg} \mathrm{N} \mathrm{kg} \mathrm{solid}{ }^{-1}$ day $^{-1}$ (Fig. 5F), with the highest average values observed in the toe-slope profile. We observed no consistent trend in the net rate of $\mathrm{NH}_{4}{ }^{+}-\mathrm{N}$ accumulation with depth, and there were no significant differences between the soil and fracture fill $(p=0.61)$.

\subsection{Soil and fracture fill water and acidity}

Soil water and acidity all varied as function of depth in the profiles (Fig. 6). Point measurements of soil water (as gravimetric water content) in samples were collected over $72 \mathrm{~h}$ during a drier period in the early fall (i.e., September) and ranged from 0.01 to $0.50 \mathrm{~g}$ water $\mathrm{g}$ soil $^{-1}$ along the catena (Fig. 6B). There was no significant difference in water content among the ridge top, mid-slope, and toe-slope sites $(p=0.27)$, but the valley floor had significantly higher soil water content than the upslope pits $(p<0.01)$. The water content tended to decrease with depth for the upland positions $(p<0.01)$, but increased with depth at the valley floor site $(p=$ 0.02). Water distribution patterns across the catena and as a function of depth were similar when gravimetric water content was compared to volumetric water content (i.e., adjusted for bulk density). Soil and fracture fill $\mathrm{pH}$ in deionized water ranged from 4.73-6.99, while the $\mathrm{CaCl}_{2}$ and $\mathrm{KCl}$ solutions ranged in $\mathrm{pH}$ from 3.96-5.64 and 3.59-4.43, respectively (Fig. 6C). There were no significant differences in soil $\mathrm{pH}$ among sites for any of the methods $(p>0.08)$. Soil $\mathrm{pH}$ tended to be similar near the soil surface among sites, but the highest $\mathrm{pH}$ values were observed in the deepest valley floor samples. There was no significant difference in acid neutralizing capacity or base neutralizing capacity among sites $(p=0.12)$. Nevertheless, both acid neutralizing capacity and base neutralizing capacity decreased with increasing depth for all the catena sites, with the deepest samples exhibiting about half the neutralizing capacity of the surface soil samples $(p<$ 0.01; Fig. 6D). 


\subsection{Elemental and mineral composition}

The $\tau$ values for $\mathrm{Al}, \mathrm{Fe}, \mathrm{K}$, and $\mathrm{Si}$, using $\mathrm{Zr}$ as the immobile element ( $\tau_{\mathrm{Zr}, j}$; Table 1; Figs. $7,8)$, were close to zero for the samples below the augerable regolith-weathered bedrock interface, indicating the chemical composition of material below this interface is similar to the parent shale. In contrast, all the major elements ( $\mathrm{Al}, \mathrm{Fe}, \mathrm{K}, \mathrm{Mg}$, and $\mathrm{Si}$ ) showed typical depletion profiles (i.e., $\tau_{\mathrm{Zr}, j}<0$; see Jin et al., 2010; Figs. 7,8) in the regolith, indicating that weathering losses mainly occurred in the regolith. We also calculated $\tau$ values for $\mathrm{K}$ and $\mathrm{Mg}$, using $\mathrm{Al}$ as the immobile element ( $\tau_{\mathrm{Al}, j}$; Table 1; Fig. 8) to distinguish solute losses from total losses. Comparing the $\tau_{\mathrm{Zr}, j}$ and $\tau_{\mathrm{Al}, j}$ values, we estimate that $68-75 \%$ of $\mathrm{K}$ and $51-63 \%$ of $\mathrm{Mg}$ depletion was caused by particles lost from the augerable regolith. Below the interface between regolith and bedrock, no significant amounts of $\mathrm{K}$ and $\mathrm{Mg}$ were observed to have been lost from the rock material as particulate transport. The $\tau$ values of fill in the shale fractures are close to those of soils just above the regolith-weathered bedrock interface (Fig. 8), with the exception of the deepest fracture material in the toe-slope that had a composition that was intermediate between the shallower fracture fill material and the parent rock.

Mineral assemblages determined by quantitative XRD analyses (Table 2) show that the soil and fracture fill have similar mineral compositions that differ from the shale bedrock. Indeed, both the soil and fracture fill have high amounts of quartz (44-69\%), while the parent shale has $<38 \%$. Clay compositions are also similar in the soil and fracture fill, with lower average illite and chlorite amounts in the soil and fracture fill, but higher average Fe-oxide and kaolinite amounts, than the shale.

\subsection{Micromorphology and SEM imaging}


In our thin section of weathered shale collected from the ridge top pit at $35 \mathrm{~cm}$ depth, we observed fractures ranging from 2 to $500 \mu \mathrm{m}$ in width in the rock matrix (Fig. 9). These fractures could have material either lining the walls that occupied $<90 \%$ of the original void space (coatings) or completely or partly filling the void space (infillings). The different coatings and infillings present in the ridge top thin section sample varied with fracture width. In detail, the shale matrix featured very small fractures (i.e., $<10 \mu \mathrm{m}$ ) that were distinguished by their $\mathrm{Fe}^{3+}$ rich coatings on the rock material and immediately adjoining the fracture surface (i.e., hypocoatings; Fig. 9A). In larger fractures that are $<50 \mu \mathrm{m}$, we observed both the hypocoatings and $\mathrm{Fe}^{3+}$-rich clay coatings or opaque coatings lining void walls. The opaque coatings may consist of Fe-Mn sesquioxides, humus, short-range order minerals, or some combination of these three materials (Stoops, 2003). In the largest fractures (generally $>50 \mu \mathrm{m}$ ), hypocoatings and coatings similar to those of the $<50 \mu \mathrm{m}$ fractures were observed on the void walls, but the (hypo)coatings were often overlain by discontinuous infillings of particulate material (i.e., clay and silt; Fig. 9E). When present, the infilling material's birefringence was speckled. Discontinuous, crescent-shaped or monostriated fabrics of birefringence characterized the infillings, presumably indicating some preferred orientation of the clay in the particulate material. We also observed circular voids in the infillings. Roots, root fragments, and other fragments of organic matter were not observed with optical microscopy in fractures in the thin sectioned rock fragment where: 1) the fractures were $<50 \mu \mathrm{m}$ and 2) the particle infilling was completely absent. Rather, these $<50 \mu \mathrm{m}$ fractures only had $\mathrm{Fe}^{3+}$-hypocoatings, $\mathrm{Fe}^{3+}$-rich clay coatings, and opaque coatings along fracture walls.

A subset of shale samples from the ridge top, mid-slope, and toe-slope $(n=18$; six per site) was also imaged with a SEM (Fig. 2H-J). We selected shale samples that featured both 
particle-filled (three per site) and particle-free fractures (three per site). The SEM imaging corroborates our findings from thin section analyses that roots were only present in fractures $>50$ $\mu \mathrm{m}$ wide. Additionally, roots were always associated with fractures containing fill, and we observed roots in all the particle-filled fractures that we imaged with SEM $(n=9)$. Often these particles were imbedded in the root sheath (Fig. 2H-J). While we always observed roots in $>50$ $\mu \mathrm{m}$, particle-filled fractures in our thin section $(n=1)$ and SEM $(n=9)$ samples, qualitative observations in the field indicate that portions of particle-filled fractures sometimes did not contain roots. In other words, in the field we always observed roots in particle-filled fractures, but roots were not always observed along the entire length of the particle-filled fracture. It is also important to note that while the roots of the tree species found in the Missed Grouse Gulch catchment would have difficulty entering fractures of $<50 \mu \mathrm{m}$, their mycorrhizal hyphae would not. However, we did not observe any evidence of hyphae in the $<50 \mu \mathrm{m}$, particle-free fractures that we imaged with SEM. In the fractures with both fill and roots, we did observe mycorrhizal hyphae along the roots and in the fracture fill material.

\subsection{Shale nanoporosity and density}

Neutron scattering measurements of porosities in the Missed Grouse Gulch shale samples reveal pores that ranged in size from $2 \mathrm{~nm}$ to about $20 \mu \mathrm{m}$ : we call this size range "nanoporosity." Shale chips recovered from depths no greater than $1.5 \mathrm{~m}$ below the land surface had higher nanoporosities than the unweathered bedrock (Fig. 10A). Indeed, porosities in the upper $1.5 \mathrm{~m}$ of the pit profiles ranged from 4 to $15 \%(n=10)$. In the bedrock, shale porosities were always $<5 \%(n=6)$, consistent with previous observations (Jin and Brantley, 2011). In the top $1.5 \mathrm{~m}$ of the profile, we did not observe any significant differences in the shale porosity for 
shale chips in the presence or absence of roots (Fig. 10A inset). As shale porosity decreased with depth, bulk chip density increased (Fig. 10B)

\section{DISCUSSION}

Most studies of the distribution of deep roots that penetrate into bedrock are restricted to arid and drought-prone environments where researchers have concluded that deep roots allow woody vegetation to access water from below the soil in weathered bedrock reserves. Thus, these studies typically focus on root activity as it relates to water stress rather than the biogeochemical dynamics of the fractured rock environment and the potential for rock weathering by roots. With our extensive physical and chemical dataset for soils, shale bedrock, and fracture fill excavated along a catena in the Missed Grouse Gulch catchment, we have not only characterized rooting depth and distribution, but also the biogeochemical environment of the deep rooting system. With these data, we observe that root densities decrease with depth, but root respiration per gram of root is similar between the soil and rock fractures. We also infer that: 1) fracture fill is formed in situ, 2) tree roots actively enhance rock weathering along bedrock fractures in shale in a temperate climate, and 3) roots may take advantage of the higher nutrients concentrations available in the rock fractures.

\subsection{Root distribution, activity, and environment in bedrock}

At the Missed Grouse Gulch catchment, we found that tree roots were most common in the augerable regolith, but were observed at every depth down to $180 \mathrm{~cm}$ beneath the land surface, including in shale bedrock fractures (Fig. 3C-D). Regional evidence suggests that roots could penetrate deeper into the bedrock than our observations (Oh and Richter, 2005). At individual sites, there was a positive correlation between root density and the fracture volume 
concentration within the rock (Fig. 3B-D), suggesting that root abundance decreases as void space in the rock decreases. However, higher root densities were observed in the upslope catena sites compared to toe-slope position for the same fracture volumes. Our field observations, root and fracture mapping efforts, thin section analysis, and SEM imaging all show that deep roots are only found in rock fractures $>50 \mu \mathrm{m}$ containing particles (i.e., clays and silts) rather than in the fractures that contain no particles but only $\mathrm{Fe}^{3+}$-rich hypocoatings (Figs. 2,9).

Many studies of arid, water-limited environments are consistent with the inference that plants grow deep roots to access water at depth (Lewis and Burgy, 1964; Zwieniecki and Newton, 1995; Hubbert et al., 2001a,b; Witty et al., 2003; Bornyasz et al., 2005; Schenk, 2008; Graham et al., 2010; Schwinning, 2010). However, isotopic analyses of tree stem water by Gaines et al. (2015) showed that the majority of trees in the adjacent Shale Hills catchment accessed soil water using shallow roots in the top $30-60 \mathrm{~cm}$ of augerable soil rather than from deep roots. This corresponds to our findings that while deep roots have similar biogeochemical effects and respiration compared to those in the upper soil, there are simply fewer roots to obtain water from these depths. In addition, water is not typically limiting in our temperate, humid catchment (Gaines et al., 2015). In fact, our results indicate that the water table may inhibit rooting depth in the downslope positions.

In detail, root distributions were not significantly different in the upper $40 \mathrm{~cm}$ of soil along the catena. Below $40 \mathrm{~cm}$ depth, we observed significantly lower root densities in the downslope catena positions compared to the upslope positions $(p<0.01)$, regardless of substrate (i.e., bedrock fractures in the toe-slope versus soil at the valley floor; Fig. 3D). On average, below $40 \mathrm{~cm}$ depth, the upslope positions had more than 10-fold higher root densities than the downslope positions. We attribute the lower root length density deeper in the profile of the 
downslope positions to the depth of the water table and $\mathrm{O}_{2}$ limitations on root growth because of near saturated soils. Indeed, our point measurements of water content (which were made immediately following a three week dry period prior to sampling) for the valley floor showed that soil water increased with depth (Fig. 6B). While we did not observe increasing water content with depth in the toe-slope immediately after excavation (which was likely due to the drier conditions), we did observed water in the bottom of the toe-slope pit (Fig. 2C), as well as valley floor pit, only a few weeks after excavation following several rainfall events. Furthermore, in November of 2013, we were unable to collect gas samples from the valley floor gas samplers at depths of $\geq 50 \mathrm{~cm}$ due to completely saturated soil pores (i.e., only water could be extracted from the samplers). This corresponds to a water table that is consistently closer to the surface in the stream valley as compared to upslope. As a result of the variable water table depth depending on the hillslope position, we observed that root abundances in the toe-slope did not begin to decrease significantly until $\sim 40 \mathrm{~cm}$ below the soil surface, while at the valley floor root densities decreased sharply around $\sim 20 \mathrm{~cm}$ (Fig. 3C,D). For upland tree species, prolonged saturation and $\mathrm{O}_{2}$ limitation presumably restricts root growth in the wetter soils in the valley of the Missed Grouse Gulch catchment (Boggie, 1977; King et al., 1986).

Interestingly, our point measurements of water content along the catena immediately following excavation show that the upper $20 \mathrm{~cm}$ of the soil contained approximately four times more water (as mass of water per mass of solid) than the fill present in the rock fractures for all the catena sites where we reached the shale bedrock (Fig. 6B), even after a three week dry period prior to sampling. We recognize that our water content values represent point measurements; nonetheless, we infer that fracture spaces in the bedrock are not consistently wetter than the overlying soils. The higher water content in the upper soil horizons could be the result of deep 
tree roots hydraulically "lifting" water from wetter zones deeper in the weathering profile (Richards and Caldwell, 1987; Brooks et al., 2002). However, water isotope data collected by Gaines et al. (2015) during the driest parts of the growing season (i.e., their observed soil moisture values were similar to those we measured in our study) indicate that trees in the nearby Shale Hills catchment mostly obtain their water from $<60 \mathrm{~cm}$ depth and generally lacked the deep root function necessary for hydraulic redistribution. Additionally, higher bulk organic matter content in the upper $20 \mathrm{~cm}$ of soil (indicated by higher total C; Fig. 4D) could hold water after rainfall events, thereby decreasing infiltration to lower soil horizons. Thus, while acquisition of water by deep roots (and possible hydraulic redistribution of that water in the weathering profile) could aid plant water balance during atypical, extreme drought conditions, our results, along with the findings of Gaines et al. (2015), suggest that the roots in temperate environments like ours generally do not need to access deep water reserves. In fact, at our site, fractures are not consistently wetter in the upland positions (Fig. 6B) and the shale matrix has a low capacity for holding water (i.e., the matrix porosity is only 0.035; Kuntz et al., 2011). In lower landscape positions, rooting into bedrock may even be inhibited by a high water table.

Our estimates of $\mathrm{CO}_{2}$ contribution rates to soil and rock fracture void space (expressed as $\mathrm{nmol} \mathrm{CO} \mathrm{Cm} \mathrm{solid}^{-3} \mathrm{~s}^{-1}$ ) from tree roots (estimated from measurements of root respiration on roots excised from the pit walls) and microbial activity (estimated from laboratory measurements of C mineralization potential; see Section 3.3) are highest for tree roots in the top $20 \mathrm{~cm}$ soil, and both total root and microbial respiration per volume of regolith decrease with increasing depth. In the rock fractures, microbial respiration is about an order of magnitude lower than plant respiration. Thus, these data imply that more of the $\mathrm{CO}_{2}$ produced in shale bedrock fractures comes from roots and their associated mycorrhizal hyphae than from microbial activity. 
While the total rate of $\mathrm{CO}_{2}$ produced per unit volume of material by both root respiration (Fig. 3E) and microbial C mineralization (Fig. 4F) decreased with depth, we observed increasing soil $\mathrm{pCO}_{2}$ with increasing depth (Fig. 4C). This is similar to most studies of soil gas versus depth (Solomon and Cerling, 1987; Pacific et al., 2008; Schulz et al., 2011; Hasenmueller et al., 2015), although our estimates of respiration extend into the rock. High $\mathrm{pCO}_{2}$ deeper in weathering profiles is generally attributed to subsurface $\mathrm{CO}_{2}$ production with low diffusive transport out of the soil at the land surface (Schulz et al., 2011; Hasenmueller et al., 2015). In other words, the $\mathrm{CO}_{2}$-depth profile is considered a diffusion profile. The profile is generally a result of the physical properties of the regolith, including water content and porosity, both of which affect $\mathrm{CO}_{2}$ production and diffusion. High moisture and low porosity inhibit the upward diffusion of $\mathrm{CO}_{2}$, thus "trapping" any $\mathrm{CO}_{2}$ produced at depth in the profile (see Hasenmueller et al., 2015). While the net rate of $\mathrm{CO}_{2}$ production decreased with depth, the overall concentration in the soil atmosphere increased, providing a potential source of acidity at depth. In addition, soil $\mathrm{pO}_{2}$ decreased with depth despite lower rates of $\mathrm{O}_{2}$ consumption at depth, again due to decreased diffusive loss.

Total $\mathrm{C}$ and total $\mathrm{N}$ concentrations (Figs. 4D,5B) were similar in both the fracture fill and shale bedrock. Thus, stores of $\mathrm{C}$ and $\mathrm{N}$ that are less accessible to tree roots and microbes were not affected by fracture microhabitats. In contrast, some of the highest inorganic $\mathrm{N}$ values were measured in the fracture fill (Figs. 5C,E), with the fracture fill in the ridge top shale having the highest inorganic $\mathrm{N}$ values of all the catena sites. Overall, there was low potential net $\mathrm{NH}_{4}{ }^{+}-$ $\mathrm{N}$ and $\mathrm{NO}_{3}{ }^{-} \mathrm{-}$ production for all the sampled sites, with some $\mathrm{NH}_{4}{ }^{+}-\mathrm{N}$ and $\mathrm{NO}_{3}{ }^{-} \mathrm{N}$ immobilization occurring at times (Figs. 5D,F). The observation of low net rates is consistent with a poorly competing or absent microbial community (i.e., at Shale Hills, nitrification rates 
have been shown to be negligible compared to mineralization rates, with the $\mathrm{NH}_{4}{ }^{+}-\mathrm{N}$ oxidizer community found to be largely absent; Weitzman, 2016). Extrapolating from our dataset, we infer that microbial processes should not lead to net accumulation or loss of $\mathrm{N}$ from the soil solution.

Given these inferences, the observed high $\mathrm{N}$ concentrations in fracture fill is puzzling. Higher concentrations of mineralized $\mathrm{N}$ associated with the fracture fill could be due to several factors. One possibility is that downward transport of $\mathrm{N}$ in solution or on particles may be the source for high inorganic $\mathrm{N}$ at depth. Just as we observe at Shale Hills (Weitzman, 2016), the dominant form of mineral $\mathrm{N}$ at Missed Grouse Gulch is $\mathrm{NH}_{4}{ }^{+}-\mathrm{N}$, with concentrations generally 10 times higher than $\mathrm{NO}_{3}{ }^{-}-\mathrm{N}$. However, $\mathrm{NH}_{4}{ }^{+}-\mathrm{N}$ is less likely to leach downward through the soil profile because soil particles tend to be negatively charged, which attracts the $\mathrm{NH}_{4}{ }^{+}-\mathrm{N}$ that is not taken up by plant roots or heterotrophic microorganisms. Thus, downward movement of $\mathrm{N}$ in solution is an unlikely cause of high mineralized $\mathrm{N}$ concentrations in the fractures. It is possible that there are preferential flowpaths, with $\mathrm{N}$ produced in surface soils being flushed through macropores deeper into the profile before it can be taken up by plants or consumed by microbes. The flushed $\mathrm{NH}_{4}{ }^{+}-\mathrm{N}$ could then be adsorbed onto the clays found within the bedrock fractures. Alternatively, clays with adsorbed $\mathrm{NH}_{4}{ }^{+}-\mathrm{N}$ may be carried with flowing water into the fractures increasing mineralized $\mathrm{N}$ concentrations, but our $\tau$ data suggest that the majority of material in the deep fractures is produced in situ (see Section 4.2). Another possibility is that $\mathrm{NH}_{4}{ }^{+}-\mathrm{N}$ could be released from clay mineral interlayers (like illite and vermiculite) as they are weathered to other clays (Nõmmik, 1965; Dahlgren, 2005; Nieder et al., 2011). Indeed, in the nearby Shale Hills catchment, it has been observed that clay minerals like illite begin to weather significantly just below the depth of refusal to hand augering (Jin et al., 2011b). Release of $\mathrm{NH}_{4}{ }^{+}-\mathrm{N}$ from clay 
weathering is also consistent with our $\tau$ data. Finally, it is also plausible that the higher concentrations of mineralized $\mathrm{N}$ associated with the fracture fill is the result of more limited plant uptake in the fractures compared to surface soils where there are more roots and microbes (hence lower mineral $\mathrm{N}$ concentrations at the surface compared to the fractures).

This suggests that the rate of $\mathrm{N}$ uptake by roots plays an important role in mineralized $\mathrm{N}$ concentrations in the fractures: roots in the fractured rock may lead to higher mineral $\mathrm{N}$ concentrations through rock weathering. Deep roots, in turn, may exploit these higher mineral $\mathrm{N}$ concentrations, which may explain their presence in the rock fractures. Our mineralogical analyses showed that the fracture fill is clay-rich, which could help attract, adsorb, and concentrate DOC and inorganic $\mathrm{N}$ onto cation exchange sites.

It is also possible that the deep roots are exploiting other nutrients like $\mathrm{K}, \mathrm{P}$, or Ca. Elemental analyses of bulk soil, fracture fill, and rock indicate that the total $\mathrm{P}$ and $\mathrm{Ca}$ of the fracture fill are similar to the lowest soil horizons and lower than the shallowest soil horizons (Table 1). However, $\mathrm{K}$ increases with depth in the weathering profile and is also higher in the fracture fill than in the overlying soils (Table 1). It is therefore possible that plant roots are exploiting the higher $\mathrm{K}$ in the fractures. Nevertheless, these elemental values represent the bulk compositions of soil, rock, and fracture fill, not the most bioavailable forms of these elements. Future work is needed to investigate bioavailable forms of these nutrients in rock fractures.

\subsection{Root-rock interactions and the potential for rock weathering}

The picture that emerges from our observations is that even in this temperate environment with a mean annual precipitation of $99 \mathrm{~cm}$, tree roots reach into the bedrock, following fractures. We observed no evidence that the roots created the fractures: indeed, the Silurian Rose Hill Formation shale bedrock has a high density of fractures due to: 1) the nature 
of the laminated rock that is known to dilate during exhumation, 2) the steep dip of the formation which allows access of water into the rock, and 3) the periglacial conditions during the Last Glacial Maximum (Jin et al., 2010). Wald et al. (2013) suggest that the weathered material in these fractures behaves in many ways like the soil, and that the chemical and physical properties of soft weathered bedrock play an important role in ecosystems. Consequently, it is important to understand the interactions between roots and fracture microhabitats.

The observation of roots only in fractures with secondary minerals could mean that deep roots are somehow associated with formation or alteration of the secondary minerals. Such an inference might also be consistent with our field, thin section, and SEM observations that small fractures did not have roots. In other words, perhaps small fractures are younger and do not allow access of roots, whereas older, wider fractures that allow such access have had time to develop fill material. Previously, Jin et al. (2010) inferred that illite weathers mainly in the mobile regolith (i.e., the augerable soil). However, as argued by Jin et al. (2010), some depletion of material below the augerable soil occurs because the composition of the soil at the point of augering refusal is not equivalent to that of bedrock at the ridge top and mid-slope positions. Data presented in this paper now show that the $\tau$ values of fracture fill in the shale are closer to those of soils than to the bedrock itself (Fig. 8). The similarity in composition between the soil and the fracture fill is consistent with weathering occurring beneath the soil-bedrock interface as argued by Jin et al. (2010).

These observations could be the result of fracture fill that is produced in situ. Indeed, the $\tau$ values of the fracture fill are close to those of soils just above the regolith-weathered bedrock interface (Fig. 8). These signatures provide clues to identify the source of the fracture fill. Clay minerals are easier to translocate than zircons (Jin et al., 2010); therefore, if the fracture fill 
originated from the soil, the $\tau_{\mathrm{Zr}, j}$ values should be higher than those for the bulk soil because zircons (containing the $\mathrm{Zr}$ ) would be left behind in the overlying soil. This process would consequently deplete $\mathrm{Zr}$ in the fracture fill. As shown in Fig. 8, the measured $\tau_{\mathrm{Zr}, j}$ values of fracture fill were much lower than inferred values if it is assumed that the fill was transported into the fractures from the soil horizons (i.e., the inferred values are assumed to contain 50\% particles from the soil layer). Moreover, the deepest fracture fill samples (i.e., those collected from the toe-slope; Fig. 8) were characterized by $\tau_{\mathrm{Zr}, j}$ values that were intermediate between the shallower fracture fill and the parent rock. This indicates that the deepest fracture fill has undergone less weathering than fracture fill higher in the weathering profile, just as the bulk rock is less weathered deeper in the profile as observed by Jin et al. (2010).

Thus, it is likely that the deep fracture fill (i.e., below the soil-rock interface) formed in situ through similar pedogenic processes that occur in the augerable regolith. Indeed, the $\tau_{\mathrm{Al}, j}$ values for the fracture fill are also similar to the lowest soil horizons indicating that elemental loss strictly as solutes is similar in both environments. Of course, we cannot disprove the possibility that particles translocated from the deepest soil horizons into the underlying fractures at depth; however, the very low $\tau$ values observed for the deep fracture fill material is most consistent with formation in situ, possibly due to organic and inorganic acid weathering by root exudates and respiration (Schulz et al., 2016). Moreover, the presence of fracture fill in horizontal fractures is further evidence that fracture fill was produced in situ and not transported from the overlying soil horizons (Schulz et al., 2016).

In addition to our observations of elemental depletion profiles, we observed mineral assemblages in the fracture fill that indicate the material has undergone weathering reactions similar to those in the soil. Both the fracture fill and soils have higher amounts of quartz, 
kaolinite, and Fe-oxides than the shale. However, the fracture fill and soil contain lower amounts of illite and chlorite compared to the parent rock.

In the thin section of shallow, weathered rock from the ridge top pit, we observed that weathered rock fractures included hypocoatings as well as three basic coatings/infillings: $\mathrm{Fe}^{3+}$ rich clay coatings, opaque coatings, and clay/silt infillings. The different coatings/infillings present in the ridge top weathered rock sample appear to vary with fracture width and are thus consistent with a size-dependent relationship between particulate material and fracture development: the silt infillings were only observed in fractures $>50$ um (Fig. 9). While hypocoatings are the result of in situ weathering processes, coatings and infillings are intrusive pedofeatures and suggest some translocation of material into the fractures (Stoops, 2003). In particular, the alignment of clay particles and crescent-shaped birefringent fabric in the fractures suggest that fracture fill in the shallow ridge top sample may have been translocated by water. These observations are at odds with our observed $\tau$ values, which suggest that fracture material at depth was formed in situ. However, our ridge top thin section was collected at $35 \mathrm{~cm}$ depth, just below the soil-rock boundary. Here, we might expect some evidence of translocation from the overlying soil into the rock fractures (Rebertus and Buol, 1985a,b; Graham and Buol, 1990; Graham and Franco-Vizcaino, 1992; Graham et al., 1994). Our samples of fracture fill used for the $\tau$ values were collected from greater depths at the ridge top (i.e., $>40 \mathrm{~cm}$; Table 1 ) due to sample volume limitations of the fracture material, and indicate in situ weathering processes dominate deeper in the profile, likely driven by activity in the rhizosphere (April and Keller, 1990; Barre et al., 2007). Furthermore, others have observed alignment and formation of clays around roots (Kodama et al., 1994; Arocena and Velde, 2009; Hinsinger et al., 2013; Schulz et 
al., 2016), indicating that in situ clay formation may also be occurring in rock fractures at shallower depths in our weathering profile.

Our $\tau$ values suggest that, at depth (i.e., below the soil-rock interface), as fractures develop and increase in size, their weathering products remain in situ. Given that fracture fill is observed only in fractures with roots, a reasonable inference is that roots in fractures play an important role in enhancing weathering through respiration, exudation of acids, and uptake of mineral-derived nutrients like K, Ca, and Mg (Fimmen et al., 2008; Graham et al., 2010; Schulz et al., 2016). In other words, secondary minerals form due to the slightly more corrosive environment in fractures with roots because of the higher $\mathrm{pCO}_{2}$ and inferred organic acid content, resulting in lower porewater $\mathrm{pH}$. Indeed, our root respiration data imply that roots and their associated mycorrhizal hyphae are an important source of $\mathrm{CO}_{2}$ in shale bedrock fractures, which, along with microbial inputs of $\mathrm{CO}_{2}$, represent an important source of acidity for rock weathering.

We also found that unweathered shale from depth had total porosity values of $<5 \%$ and limited pore connectivity, but rock fragments recovered from soil (i.e., $<1.5 \mathrm{~m}$ deep) had higher porosity and connectivity (Fig. 10A). Brantley et al. (2014) observed that on ridge tops, the porosity of rock fragments decreased from the surface to the regolith-bedrock interface, while on slopes the porosity slightly increased with depth in the soil. We might expect to see higher porosity in shale rock chips that are in direct contact with tree roots as acids produced by the roots enhance surface porosity via mineral dissolution. However, in the top $1.5 \mathrm{~m}$ of the profile, we did not observe significant differences in porosity between shale that was in contact with tree roots and shale that was not (Fig. 10A). We therefore attribute the increase in porosity in shale 
above $5 \mathrm{~m}$ to fracturing of the rock, perhaps driven by periglacial conditions during the Last Glacial Maximum or Holocene regolith weathering, not to plants or roots.

In contrast, we did observe fill near roots in the bedrock fractures, suggesting that rock weathering is related to the presence of tree roots. We therefore infer that when root acids corrode the shale along the fractures, the pores that form due to mineral dissolution coalesce rapidly and cause spalling of particles off of the shale surface. Consequently, the porosities of shale surfaces along fractures where roots occur are comparable to shale surfaces that are not near roots because particles form quickly via root-induced weathering. This latter point explains the similarity between the porosity measurements obtained by neutron scattering for shale in contact with roots and shale not in contact with roots (Fig. 10A).

\section{CONCLUSIONS}

We have presented one of the most extensive physical and chemical datasets available for soils, shale bedrock, and fractures in a weathering system. We focused on pits excavated along a catena in the Missed Grouse Gulch catchment that is equivalent to the better known Shale Hills catchment in the SSHCZO. The pits show that plant roots are able to penetrate fractured bedrock to depths of $180 \mathrm{~cm}$ (and likely go much deeper). Overall, our data suggest that the roots and fracture fill in shale bedrock along our catena are similar to roots and soils in surface soil horizons. The main difference between the soil above and environment of the roots in the rock fractures is that there are fewer roots and fewer secondary minerals present in the fractures.

However, these deep roots and their microbial symbionts create an ecosystem designed for chemical weathering to release mineral nutrients. The clear evidence for this process is found in the bedrock along the fractures where fill material is observed. A key observation in this regard is that roots were only observed in filled fractures and fracture fill was only observed in 
fractures with roots. Moreover, we found that in humid regions deep roots in rock fractures are not routinely exploiting higher water content in the dry season, and indeed, in lower landscape positions high water content at depth may be inhibiting root exploration of bedrock. It is possible that roots may access water reserves during extreme drought conditions, but given our geochemical data we infer that the deep roots penetrate the rock to access deeper nutrients that are not abundant or available in the soil. Indeed, root biomass may take advantage of higher mineral $\mathrm{N}$ or $\mathrm{K}$ concentrations in these rock fractures (though fracture nutrients do not account for the majority of uptake by woody plant roots due to the small number of roots exploiting resources in the fractures). Our findings highlight the importance of bedrock fractures as a habitable medium for terrestrial ecosystems as well as role of plants roots in regolith formation rates.

\section{ACKNOWLEDGMENTS}

We thank Joseph Harding, Brosi Bradley, and numerous undergraduate assistants for data collection and technical assistance. We conducted this research at the Penn State Stone Valley Forest, which is funded by The Pennsylvania State University College of Agricultural Sciences, Department of Ecosystem Science and Management and managed by the staff of the Forestlands Management Office. We thank Marjorie Schulz and an anonymous reviewer who provided constructive comments that helped us improve the manuscript. Financial support was provided by National Science Foundation (NSF) grants EAR-0725019 (Christopher J. Duffy), EAR1239285 (Susan L. Brantley), and EAR-1331726 (Susan L. Brantley) for the Susquehanna Shale Hills Critical Zone Observatory. Logistical support and data were provided by the NSFsupported Susquehanna Shale Hills Critical Zone Observatory. 


\section{REFERENCES}

Ahmed E., Holmström, S.J.M., 2015, Microbe-mineral interactions: the impact of surface attachment on mineral weathering and element selectivity by microorganisms. Chemical Geology, 403, 13-23.

Anderson, S.P., Dietrich, W.E., Brimhall, G.H., 2002, Weathering profiles, mass-balance analysis, and rates of solute loss: Linkages between weathering and erosion in a small, steep catchment. Geological Society of America Bulletin, 114, 1143-1158.

Anderson, M.A., Graham, R.C., Alyanakian, G.J., Martynn, D.Z., 1995, Late summer water status of soils and weathered bedrock in a giant sequoia grove. Soil Science, 190, 415-422.

Andrews, D.M., Lin, H., Zhu, Q., Jin, L., Brantley, S.L., 2011, Hot spots and hot moments of dissolved organic carbon export and soil organic carbon storage in the Shale Hills catchment. Vadose Zone Journal, 10, 943-954.

April, R., Keller, D., 1990, Mineralogy of the rhizosphere in forest soils of the eastern United States. Biogeochemistry, 9, 1-18.

Arocena, J.M., Velde, B., 2009, Transformation of chlorites by primary biological agents-a synthesis of X-ray diffraction studies. Geomicrobiology Journal, 26, 382-388.

Balogh-Brunstad, Z., Keller, C.K., Gill, R.A., Bormann, B.T., Li, C.Y., 2008, The effect of bacteria and fungi on chemical weathering and chemical denudation fluxes in pine growth experiments. Biogeochemistry, 88, 153-167.

Barre, P., Velde, B., Catel, N., Abbadie, L., 2007, Soil-plant potassium transfer: Impact of plant activity on clay minerals as seen from X-ray diffraction. Plant and Soil, 292, 137-146.

Berg, T.M., Edmunds, W.E., Geyer, A.R., and others (compilers), 1980, Geologic map of Pennsylvania. 4th Ser., Map 1. Harrisburg, PA. Pennsylvania Geological Survey.

Binkley, D., Hart, S.C., 1989, The components of nitrogen availability assessments in forest soils. Advances in Soil Science, 10, 57-112.

Binkley D., Sollins, P., 1990, Factors determining difference in soil pH in adjacent conifer and alder-conifer stands. Society of America Journal 54, 1427-1433.

Binkley, D., Valentine, D., Wells, C., Valentine, U., 1989, An empirical analysis of the factors contributing to 20 -year decrease in soil $\mathrm{pH}$ in an old-field plantation of loblolly pine.

Biogeochemistry, 8, 39-54.

Blake, G.R., Hartge, K.H., 1986, Particle density. Methods of Soil Analysis: Part 1—Physical and Mineralogical Methods, 377-382. 
Bloom, A.J., Sukrapanna, S.S., Warner, R.L., 1992, Root respiration associated with ammonium and nitrate absorption and assimilation by barley. Plant Physiology, 99, 1294-1301.

Bornyasz, M.A., Graham, R.C., Allen, M.F., 2005, Ectomycorrhizae in a soil-weathered granitic bedrock regolith: linking matrix resources to plants. Geoderma, 126, 141-160.

Boggie, R., 1977, Water-table depth and oxygen content of deep peat in relation to root growth of Pinus contorta. Plant and Soil, 48, 447-454.

Brantley, S.L., 2010, Weathering: rock to regolith. Nature Geoscience, 3, 305-306.

Brantley, S.L., Holleran, M., Jin, L., and Bazilevskaya, E., 2013, Probing deep weathering in the Shale Hills Critical Zone Observatory, Pennsylvania (USA): the hypothesis of nested chemical reaction fronts in the subsurface. Earth Surface Processes and Landforms, 38, 1280-1298.

Brantley, S.L., Lin, H., Sullivan, P.L., Gu, X., Hasenmueller, E.A., Kaye, J.P., 2014, Exploring how rock turns to regolith at the Susquehanna Shale Hills Critical Zone Observatory, central Pennsylvania. Geological Society of America Abstracts with Programs, 46, 2, 72.

Brimhall, G.H., Dietrich, W.E., 1987, Constitutive mass balance relations between chemical composition, volume, density, porosity, and strain in metasomatic hydrochemical systems: results on weathering and pedogenesis. Geochimica et Cosmochimica Acta, 51, 567-587.

Brooks, J.R., Meinzer, F.C., Coulombe, R., Gregg, J., 2002, Hydraulic redistribution of soil water during summer drought in two contrasting Pacific Northwest coniferous forests. Tree Physiology, 22, 1107-1117.

Burton, A.J., Melillo, J.M., Frey, S.D., 2008, Adjustment of forest ecosystem root respiration as temperature warms. Journal of Integrative Plant Biology, 50, 1467-1483.

Canadell, J., Zedler, P.H., 1995, Underground structures of woody plants in Mediterranean ecosystems of Australia, California, and Chile. Ecological Studies, 108, 177-210.

Dahlgren, R.A., 2005, Geologic nitrogen as a source of soil acidity. Soil Science and Plant Nutrition, 51, 719-723.

Dauer, J.M., Withington, J.M., Oleksyn, J., Chorover, J., Chadwick, O.A., Reich, P.B., Eissenstat, D.M., 2009, A scanner-based approach to soil profile-wall mapping of root distribution. Dendrobiology, 62, 35-40.

Doane T.A., Horwath W.R., 2003, Spectrophotometric determination of nitrate with a single reagent. Analytical Letters, 36, 2713-2722.

Duniway, M.C., Herrick, J.E., Monger, H.C., 2010, Spatial and temporal variability of plantavailable water in calcium carbonate-cemented soils and consequences for arid ecosystem resilience. Oecologia, 163, 215-226. 
Egerton-Warburton, L.M., Graham, R.C., Hubbert, K.R., 2003, Spatial variability in mycorrhizal hyphae and nutrient and water availability in a soil-weathered bedrock profile. Plant and Soil, 249, 331-342.

Escamilla, J.A., Comerford, N.B., Neary, D.G., 1991, Soil-core break method to estimate pine root distribution. Soil Science Society of America Journal, 55, 1722-1726.

Estrada-Medina, H., Graham, R.C., Allen, M.F., Jiménez-Osornio J.J., Robles-Casolco, S., 2013, The importance of limestone bedrock and dissolution karst features on tree root distribution in northern Yucatán, México. Plant Soil, 362, 37-50.

Feldman C. 1983. Behavior of trace refractory minerals in the lithium metaborate fusion acid dissolution procedure. Analytical Chemistry, 55, 2451-2453.

Fimmen, R.L., Vasudevan, D., Williams, M.A., West, L.T., 2008, Rhizogenic Fe-C redox cycling: a hypothetical biogeochemical mechanism that drives crustal weathering in upland soils. Biogeochemistry, 87, 127-141.

Frazier, C.S., Graham, R.C., 2000, Pedogenic transformation of fractured granitic bedrock, southern California. Soil Science Society of America Journal, 64, 2057-2069.

Gaines, K.P., Stanley, J.W., Meinzer, F.C., McCulloh, K.A., Woodruff, D.R., Chen, W., Adams, T.S., Lin, H., Eissenstat, D.M., 2015, Reliance on shallow soil water in a mixed-hardwood forest in central Pennsylvania. Tree Physiology, 36, 444-458.

Gale, M.R., Grigal, D.F., 1987, Vertical root distributions of northern tree species in relation to successional status. Canadian Journal of Forest Research, 17, 829-834.

Gardner, W.H., Klute, A., 1986, Water content. In: Methods of soil analysis. Part 1. Physical and mineralogical methods, A. Klute (ed.), Agronomy, 9, 493-544.

Graham, R.C., Buol, S.W., 1990, Soil-Geomorphic relations on the Blue Ridge Front: II. Soil characteristics and pedogenesis. Soil Science Society of America Journal, 54, 1367-1377.

Graham, R.C., Franco-Vizcaino, E., 1992, Soils on igneous and metavolcanic rocks in the Sonoran Desert of Baja California, Mexico. Geoderma, 54, 1-21.

Graham, R.C., Guertal, W.R., Tice, K.R., 1994, The pedogenic nature of weathered rock. In: Whole regolith pedology, D.L. Cremeens et al. (eds.), Soil Science Society of America Special Publication 34. Soil Science Society of America, Madison, WI, 21-40.

Graham, R.C., Rossi, A.M., Hubbert, K.R., 2010, Rock to regolith conversion: producing hospitable substrates for terrestrial ecosystems. GSA Today, 20, 4-9.

Hart, S.C., Stark, J.M., 1997, Nitrogen limitation of the microbial biomass in old-growth forest soil. Ecoscience, 4, 91-98. 
Hart, S.C., Stark, J.M., Davidson, E.A., Firestone, M.K., 1994, Nitrogen mineralization, immobilization, and nitrification. In: Methods of soil analysis, Part 2, Weaver, R.W., Angle S., Bottomley P., Bezdicek D., Smith S., Tabatabi A., Wollum A. (eds.). Soil Science Society of America Book Series, No. 5, Madison, 985-1018.

Hasenmueller, E.A., Jin, L., Stinchcomb, G.E., Lin, H., Brantley, S.L., Kaye, J.P., 2015, Topographic controls on the depth distribution of soil $\mathrm{CO}_{2}$ in a small temperate watershed. Applied Geochemistry, 63, 58-69.

Hasselquist, N.J., Allen, M.F., Santiago, L.S., 2010, Water relations of evergreen and droughtdeciduous trees along a seasonally dry tropical forest chronosequence. Oecologia, 164, 881-890.

Hellmers, H., Horton, S., Juhren, G., O’Keefe, J., 1955, Root systems of some chaparral plants in southern California. Ecology, 36, 667-678.

Hinsinger, P., 2013, Plant-induced changes in soil processes and properties. Soil Conditions and Plant Growth, 323-365.

Hubbert, K.R., Beyers, J.L., Graham, R.C., 2001a. Roles of weathered bedrock and soil in seasonal water relations of Pinus jeffreyi and Arctostaphylos patula. Canadian Journal of Forest Research, 31, 1947-1957.

Hubbert, K.R., Graham, R.C., Anderson, M.A., 2001b, Soil and weathered bedrock: components of a Jeffrey pine plantation substrate. Soil Science Society of America Journal, 65, 1255-1262.

Jackson, C.T., 1840, Report on the geological and agricultural survey of the State of Rhode Island, Providence: B. Cranston \& Co.

Jackson, R.B., Moore, L.A., Hoffmann, W., Pockman, W.T., Linder, C.R., 1999, Ecosystem rooting depth determined with caves and DNA. Proceedings of the National Academy of Sciences, 96, 11387-11392.

Jin, L., Andrews, D.M., Holmes, G.H., Lin, H., Brantley, S.L., 2011a, Opening the "black box": water chemistry reveals hydrological controls on weathering in the Susquehanna Shale Hills Critical Zone Observatory. Vadose Zone Journal, 10, 928-942.

Jin, L., Brantley, S.L., 2011, Soil chemistry and shale weathering on a hillslope influenced by convergent hydrologic flow regime at the Susquehanna/Shale Hills Critical Zone Observatory. Applied Geochemistry, 26, S51-S56.

Jin, L., Ogrinc, N., Yesavage, T., Hasenmueller, E.A., Ma, L., Sullivan, P.L., Kaye, J., Duffy, C., Brantley, S.L., 2014, The $\mathrm{CO}_{2}$ consumption potential during gray shale weathering: insights from the evolution of carbon isotopes in the Susquehanna Shale Hills critical zone observatory. Geochimica et Cosmochimica Acta, 142, 260-280. 
Jin, L., Rother, G., Cole, D.R., Mildner, D.F.R., Duffy, C.J., Brantley, S.L., 2011b, Characterization of deep weathering and nanoporosity development in shale - a neutron study. American Mineralogist, 96, 498-512.

Jin, L., Ravella, R., Ketchum, B., Bierman, P.R., Heaney, P., White, T., Brantley, S.L., 2010, Mineral weathering and elemental transport during hillslope evolution at the Susquehanna/Shale Hills Critical Zone Observatory. Geochimica et Cosmochimica Acta, 74, 3669-3691.

King, J.A., Smith, K.A., Pyatt, D.G., 1986, Water and oxygen regimes under conifer plantations and native vegetation on upland peaty gley soil and deep peat soils. European Journal of Soil Science, 37, 485-497.

Kochenderfer, J.N., 1973, Root distribution under some forest types native to West Virginia. Ecology, 54, 445-448.

Kodama, H., Nelson, S., Yang, A.F., Kohyama, N., 1994, Mineralogy of rhizospheric and nonrhizospheric soils in corn fields. Clays and Clay Minerals, 42, 755-763.

Kuntz, B.W., Rubin, S., Berkowitz, B., Singha, K., 2011, Quantifying solute transport at the Shale Hills critical zone observatory. Vadose Zone Journal, 10, 843-857.

Leake, J.R., Duran, A.L., Hardy, K.E., Johnson, I., Beerling, D.J., Banwart, S.A., Smits, M.M., 2008, Biological weathering in soil: the role of symbiotic root-associated fungi biosensing minerals and directing photosynthate-energy into grain-scale mineral weathering. Mineralogical Magazine, 72, 85-89.

Lewis, D.C., Burgy, R.H., 1964, The relationship between oak tree roots and groundwater in fractured rock as determined by tritium tracing. Journal of Geophysical Research, 69, 2579-2588.

LI-COR, 2007, LI-7000 $\mathrm{CO}_{2} / \mathrm{H}_{2} \mathrm{O}$ analyzer instruction manual. LI-COR Biosciences, Lincoln, NE, 1-240.

Lin, H., 2006, Temporal stability of soil moisture spatial pattern and subsurface preferential flow pathways in the Shale Hills Catchment. Vadose Zone Journal, 5, 317-340.

Ma, L., Chabaux, F., Pelt, E., Blaes, E., Jin, L., Brantley, S.L., 2010, Regolith production rates calculated with uranium-series isotopes at the Susquehanna/Shale Hills Critical Zone Observatory. Earth and Planetary Science Letters, 297, 211-225.

Ma, L., Chabaux, F., West, N., Kirby, E., Jin, L., Brantley, S.L., 2013, Regolith production and transport in the Susquehanna Shale Hills Critical Zone Observatory, Part 1: Insights from Useries isotopes. Journal of Geophysical Research, Earth Surface, 118, 722-740.

Ma, L., Jin, L., Brantley, S.L., 2011a, Geochemical behaviors of different element groups during shale weathering at the Susquehanna/Shale Hills Critical Zone Observatory. Applied Geochemistry, 26, S89-S93. 
Ma, L., Jin, L., Brantley, S.L., 2011b, How mineralogy and slope aspect affect REE release and fractionation during shale weathering in the Susquehanna/Shale Hills Critical Zone Observatory. Chemical Geology, 290, 31-49.

Maeght J., Rewald, B., Pierret, A., 2013, How to study deep roots - and why it matters. Frontiers in Plant Science, 4, 1-14.

Matejovic, I., 1997, Determination of carbon and nitrogen in samples of various soils by dry combustion, Communications in Soil Science and Plant Analysis, 28, 1499-1511.

National Oceanic and Atmospheric Administration (NOAA), 2016, Climate Data Online: Dataset Discovery. Climate Data Online Web page, https://www.ncdc.noaa.gov/cdo-web/datasets.

Nicoll, B.C., Gardiner, B.A., Rayner, B., Peace, A.J., 2006, Anchorage of coniferous trees in relation to species, soil type, and rooting depth. Canadian Journal of Forest Research, 36, 18711883.

Nieder, R., Benbi, D.K., Scherer, H.W., 2011, Fixation and defixation of ammonium in soils: a review. Biology and Fertility of Soils, 47, 1-14.

Nõmmik, H., 1965, Ammonium fixation and other reactions involving non-enzymatic immobilization of mineral nitrogen in soils. In: Soil nitrogen, Bartholomew, W.V., Clark, F.E. (eds.). American Society of Agronomy, No. 10, 198-258.

Oh, N.H., Richter, D.D., 2005, Elemental translocation and loss from three highly weathered soil-bedrock profiles in the southeastern United States. Geoderma, 126, 5-25.

Pacific, V., McGlynn, B., Riveros-Iregui, D., Welsch, D. and Epstein, H., 2008, Variability in soil respiration across riparian-hillslope transitions. Biogeochemistry, 91, 51-70.

Paul, J.M., Mathur, R., Brantley, S.L., Jin, L., 2010, A study of physical and chemical weathering of the Marcellus Shale in central Pennsylvania, Geological Society of America Abstracts with Programs, 42, 5, 287.

Poot, P., Hopper, S.D., van Diggelen, J.M.H., 2012, Exploring rock fissures: does a specialized root morphology explain endemism on granite outcrops? Annals of Botany, 110, 291-300.

Rebertus, R.A., Buol, S.W., 1985a, Intermittency of illuviation in dystrochrepts and hapludults from the Piedmont and Blue Ridge provinces of North Carolina. Geoderma, 36, 277-291.

Rebertus, R.A., Buol, S.W., 1985b, Iron distribution in a developmental sequence of soils from mica gneiss and schist. Soil Science Society of America Journal, 49, 713-720.

Reneau, S.L., Dietrich, W.E., 1991, Erosion rates in the southern Oregon Coast Range: evidence for an equilibrium between hillslope erosion and sediment yield. Earth Surface Processes and Landforms, 16, 307-322. 
Richards, J.H., Caldwell, M.M., 1987, Hydraulic lift: substantial nocturnal water transport between soil layers by Artemisia tridentata roots. Oecologia, 73, 486-489.

Rose, K., Graham, R., Parker, D., 2003, Water source utilization by Pinus jeffreyi and Arctostaphylos patula on thin soils over bedrock. Oecologia, 134, 46-54.

Schenk, H.J., 2008, Soil depth, plant rooting strategies and species' niches. New Phytologist, $178,223-225$.

Schenk, H.J., Jackson, R.B., 2002a, Rooting depths, lateral root spreads and belowground/above-ground allometries of plants in water-limited ecosystems. Journal of Ecology, 90, 480-494.

Schenk, H.J., Jackson, R.B., 2002b, The global biogeography of roots. Ecological Monographs, 72, 311-328.

Schenk, H.J., Jackson, R.B., 2005, Mapping the global distribution of deep roots in relation to climate and soil characteristics. Geoderma, 126, 129-140.

Scholl, D.G., 1976, Soil moisture flux and evapotranspiration determined from soil hydraulic properties in a chaparral stand. Soil Science Society of America Journal, 40, 14-18.

Schulz, M., Stonestrom, D., Lawrence, C., Bullen, T., Fitzpatrick, J., Kyker-Snowman, E., Manning, J., Mnich, M., 2016, Structured heterogeneity in a marine terrace chronosequence: Upland mottling. Vadose Zone Journal, 15.

Schulz, M., Stonestrom, D., Von Kiparski, G., Lawrence, C., Masiello, C., White, A., Fitzpatrick, J., 2011, Seasonal dynamics of $\mathrm{CO}_{2}$ profiles across a soil chronosequence, Santa Cruz, California. Applied Geochemistry, 26, S132-S134.

Schwinning, S., 2010, The ecohydrology of roots in rocks. Ecohydrology, 3, 238-245.

Sims, G.K., Ellsworth, T.R., Mulvaney, R.L., 1995, Microscale determination of inorganic nitrogen in water and soil extracts. Communications in Soil Science \& Plant Analysis, 26, 303316.

Solomon, D.K., Cerling, T.E., 1987, The annual carbon dioxide cycle in a montane soil: observations, modeling, and implications for weathering. Water Resources Research, 23, 22572265.

Sternberg, P.D., Anderson, M.A., Graham, R.C., Beyers, J.L., Tice, K.R., 1996, Root distribution and seasonal water status in weathered granitic bedrock under chaparral. Geoderma, 72, 89-98.

Stone, E.L., Kalisz, P.J., 1991, On the maximum extent of tree roots. Forest Ecology and Management, 46, 59-102. 
Stoops, G., 2003, Guidelines for Analysis and Description of Soil and Regolith Thin Sections. Soil Science Society of America, Inc., Madison, Wisconsin, USA.

Sullivan, P.L., Hynek, S., Gu, X., Singha, K., White, T., West, N., Kim, H., Clarke, B., Kirby, E., Duffy, C., Brantley, S.L., 2016, Oxidative dissolution under channel leads geomorphological evolution at the Shale Hills Catchment. American Journal of Science, 316, 981-1026.

Van Breemen, N., Finlay, R., Lundström, U., Jongmans, A.G., Giesler, R., Olsson M., 2000, Mycorrhizal weathering: A true case of mineral plant nutrition? Biogeochemistry, 49, 53-67.

Wald, J.A., Graham, R.C., Schoeneberger, P.J., 2013, Distribution and properties of soft weathered bedrock at $\leq 1 \mathrm{~m}$ depth in the contiguous United States. Earth Surface Processes and Landforms, 38, 614-626.

Walker, D.A., 1987, The use of the oxygen electrode and fluorescence probes in simple measurements of photosynthesis. Oxygraphics Ltd., Sheffield, Packard Publishing Ltd., Chichester \& Hansatech Instruments Ltd., King's Lynn.

Weitzman, J.N., 2016, Variation in soil nitrogen retention across land uses, landscapes, and landforms in central Pennsylvania. Ph.D. dissertation, The Pennsylvania State University.

Weitzman, J.N., Forshay, K.J., Kaye, J.P., Mayer, P.M., Koval, J.C., Walter, R.C., 2014, Potential nitrogen and carbon processing in a landscape rich in milldam legacy sediments. Biogeochemistry, 120, 337-357.

West, N., Kirby, E., Bierman, P., Clarke, B.A., 2014, Aspect-dependent variations in regolith creep revealed by meteoric ${ }^{10} \mathrm{Be}$. Geology, 42, 507-510.

West, N., Kirby, E., Bierman, P., Slingerland, R., Ma, L., Rood, D., Brantley, S., 2013, Regolith production and transport in the Susquehanna Shale Hills Critical Zone Observatory, Part 2: Insights from meteoric 10Be. Journal of Geophysical Research, Earth Surface, 118, 1877-1896.

Witty, J.H., Graham, R.C., Hubbert, K.R., Doolittle, J.A., Wald, J.A., 2003, Contributions of water supply from the weathered bedrock zone to forest soil quality. Geoderma, 114, 389-400.

Yesavage, T., Fantle, M.S., Vervoort, J., Mathur, R., Jin, L., Liermann, L.J., Brantley, S.L., 2012, Fe cycling in the Shale Hills Critical Zone Observatory, Pennsylvania: an analysis of biogeochemical weathering and $\mathrm{Fe}$ isotope fractionation. Geochimica et Cosmochimica Acta, 99, 18-38.

Zwieniecki, M.A., Newton, M., 1995, Roots growing in rock fissures: their morphological adaptation. Plant and Soil, 172, 181-187. 


\section{TABLES}

Table 1. Elemental concentrations and corresponding $\tau_{\mathrm{Zr}, j}$ and $\tau_{\mathrm{Al}, j}$ values of bulk soil, rock, or fracture fill along the Missed Grouse Gulch planar slope catena.

\begin{tabular}{|c|c|c|c|c|c|c|c|c|c|c|c|c|c|c|c|c|c|c|c|c|c|c|c|c|}
\hline \multirow[b]{2}{*}{$\begin{array}{l}\text { Depth } \\
\text { (cm) }\end{array}$} & \multicolumn{12}{|c|}{ Elemental concentration } & \multicolumn{10}{|c|}{$\tau_{\mathrm{Zr}, j}$ values } & \multicolumn{2}{|c|}{$\tau_{\mathrm{Al}, j}$ values } \\
\hline & $\begin{array}{c}\mathrm{Al} \\
(\%)\end{array}$ & $\begin{array}{l}\mathrm{Ca} \\
(\%)\end{array}$ & $\begin{array}{l}\mathrm{Fe} \\
(\%)\end{array}$ & $\begin{array}{c}\mathrm{K} \\
(\%) \\
\end{array}$ & $\begin{array}{l}\mathrm{Mg} \\
(\%)\end{array}$ & $\begin{array}{l}\mathrm{Mn} \\
(\%)\end{array}$ & $\begin{array}{l}\mathrm{Na} \\
(\%)\end{array}$ & $\begin{array}{c}\begin{array}{c}P \\
(\%)\end{array} \\
\end{array}$ & $\begin{array}{c}\mathrm{Si} \\
(\%)\end{array}$ & $\begin{array}{c}\mathrm{Ti} \\
(\%)\end{array}$ & $\begin{array}{l}\text { LOI } \\
(\%)\end{array}$ & $\begin{array}{c}\mathrm{Zr} \\
(\mathrm{ppm})\end{array}$ & $\mathrm{Al}$ & $\mathrm{Ca}$ & $\mathrm{Fe}$ & $\mathrm{K}$ & $\mathrm{Mg}$ & $\mathrm{Mn}$ & $\mathrm{Na}$ & $P$ & $\mathrm{Si}$ & $\mathrm{Ti}$ & $\mathrm{K}$ & $\mathrm{Mg}$ \\
\hline \multicolumn{25}{|c|}{ Ridge top soil or rock } \\
\hline $3-7$ & 8.29 & 0.13 & 4.68 & 2.22 & 0.53 & 0.41 & 0.25 & 0.09 & 27.73 & 0.67 & 12.51 & 259 & -0.54 & -0.02 & -0.51 & -0.66 & -0.75 & 5.12 & -0.51 & 0.41 & -0.39 & -0.33 & -0.26 & -0.46 \\
\hline $9-13$ & 8.63 & 0.11 & 4.80 & 2.37 & 0.56 & 0.39 & 0.25 & 0.09 & 27.35 & 0.66 & 11.89 & 239 & -0.48 & -0.08 & -0.45 & -0.60 & -0.71 & 5.37 & -0.45 & 0.54 & -0.35 & -0.27 & -0.24 & -0.45 \\
\hline $15-21$ & 8.71 & 0.05 & 4.92 & 2.54 & 0.55 & 0.15 & 0.26 & 0.12 & 29.90 & 0.71 & 7.13 & 264 & -0.52 & -0.62 & -0.49 & -0.61 & -0.74 & 1.17 & -0.50 & 0.70 & -0.35 & -0.30 & -0.19 & -0.46 \\
\hline $30-36$ & 9.29 & 0.04 & 4.83 & 3.06 & 0.60 & 0.06 & 0.27 & 0.09 & 28.75 & 0.67 & 6.10 & 235 & -0.43 & -0.67 & -0.44 & -0.48 & -0.69 & -0.05 & -0.41 & 0.47 & -0.30 & -0.25 & -0.09 & -0.45 \\
\hline $40-44$ & 11.79 & 0.05 & 5.24 & 4.59 & 0.84 & 0.01 & 0.33 & 0.05 & 25.91 & 0.62 & 6.31 & 152 & 0.12 & -0.36 & -0.06 & 0.21 & -0.32 & -0.74 & 0.11 & 0.21 & -0.03 & 0.06 & 0.08 & -0.39 \\
\hline $48-52$ & 11.14 & 0.06 & 5.20 & 4.14 & 0.86 & 0.01 & 0.28 & 0.06 & 26.92 & 0.59 & 5.94 & 162 & 0.00 & -0.32 & -0.12 & 0.03 & -0.34 & -0.81 & -0.12 & 0.38 & -0.05 & -0.04 & 0.03 & -0.34 \\
\hline $100-104$ & 11.26 & 0.08 & 5.23 & 4.21 & 0.86 & 0.01 & 0.28 & 0.04 & 26.86 & 0.60 & 6.05 & 152 & 0.07 & -0.02 & -0.06 & 0.11 & -0.31 & -0.82 & -0.04 & 0.00 & 0.00 & 0.03 & 0.04 & -0.35 \\
\hline $128-132$ & 11.39 & 0.08 & 5.62 & 4.18 & 0.90 & 0.01 & 0.27 & 0.05 & 26.45 & 0.59 & 6.02 & 149 & 0.11 & 0.03 & 0.03 & 0.13 & -0.26 & -0.80 & -0.06 & 0.41 & 0.01 & 0.04 & 0.02 & -0.33 \\
\hline \multicolumn{25}{|c|}{ Ridge top fracture fill } \\
\hline $40-90$ & 9.10 & 0.06 & 6.21 & 3.34 & 0.58 & 0.01 & 0.24 & 0.05 & 28.96 & 0.61 & 6.50 & 195 & -0.32 & -0.36 & -0.13 & -0.31 & -0.63 & -0.82 & -0.37 & -0.11 & -0.15 & -0.17 & 0.02 & -0.46 \\
\hline \multicolumn{25}{|c|}{ Mid-slope soil or rock } \\
\hline $3-7$ & 8.51 & 0.11 & 4.32 & 2.42 & 0.62 & 0.25 & 0.24 & 0.09 & 28.59 & 0.70 & 10.52 & 248 & -0.50 & -0.10 & -0.52 & -0.61 & -0.69 & 2.84 & -0.50 & 0.34 & -0.34 & -0.25 & -0.21 & -0.39 \\
\hline $10-14$ & 8.88 & 0.07 & 4.51 & 2.55 & 0.60 & 0.26 & 0.23 & 0.08 & 29.28 & 0.72 & 8.29 & 256 & -0.50 & -0.48 & -0.52 & -0.60 & -0.71 & 2.96 & -0.53 & 0.24 & -0.35 & -0.26 & -0.21 & -0.42 \\
\hline $19-25$ & 9.15 & 0.08 & 4.74 & 2.77 & 0.67 & 0.13 & 0.23 & 0.08 & 29.48 & 0.70 & 6.32 & 253 & -0.48 & -0.38 & -0.49 & -0.56 & -0.67 & 0.93 & -0.53 & 0.28 & -0.34 & -0.28 & -0.16 & -0.38 \\
\hline $37-47$ & 7.76 & 0.11 & 4.09 & 2.54 & 0.60 & 0.05 & 0.28 & 0.04 & 31.66 & 0.69 & 5.14 & 356 & -0.68 & -0.41 & -0.69 & -0.71 & -0.79 & -0.50 & -0.59 & -0.59 & -0.49 & -0.49 & -0.09 & -0.34 \\
\hline 78-92 & 10.77 & 0.09 & 5.09 & 3.95 & 1.09 & 0.05 & 0.28 & 0.06 & 27.58 & 0.59 & 5.34 & 175 & -0.11 & -0.05 & -0.20 & -0.09 & -0.23 & 0.08 & -0.18 & 0.41 & -0.10 & -0.11 & 0.02 & -0.14 \\
\hline $105-112$ & 10.32 & 0.06 & 5.76 & 3.56 & 1.18 & 0.07 & 0.24 & 0.03 & 27.84 & 0.57 & 5.56 & 168 & -0.11 & -0.31 & -0.07 & -0.15 & -0.14 & 0.71 & -0.27 & -0.20 & -0.06 & -0.11 & -0.04 & -0.03 \\
\hline $113-133$ & 10.73 & 0.09 & 5.56 & 4.06 & 1.12 & 0.04 & 0.27 & 0.04 & 26.95 & 0.58 & 6.21 & 157 & -0.01 & 0.06 & -0.03 & 0.04 & -0.12 & 0.00 & -0.12 & -0.02 & -0.02 & -0.02 & 0.05 & -0.11 \\
\hline \multicolumn{25}{|c|}{ Mid-slope fracture fill } \\
\hline $120-126$ & 7.65 & 0.09 & 3.21 & 2.76 & 0.55 & 0.03 & 0.30 & 0.04 & 32.30 & 0.69 & 5.22 & 278 & -0.60 & -0.39 & -0.68 & -0.60 & -0.76 & -0.64 & -0.45 & -0.49 & -0.34 & -0.35 & 0.00 & -0.39 \\
\hline \multicolumn{25}{|c|}{ Toe-slope soil or rock } \\
\hline $3-7$ & 7.33 & 0.09 & 3.89 & 2.36 & 0.52 & 0.29 & 0.22 & 0.07 & 29.97 & 0.68 & 10.58 & 253 & -0.58 & -0.34 & -0.58 & -0.63 & -0.75 & 3.39 & -0.56 & 0.12 & -0.33 & -0.29 & -0.11 & -0.39 \\
\hline $9-13$ & 7.59 & 0.07 & 3.68 & 2.42 & 0.54 & 0.18 & 0.23 & 0.06 & 31.32 & 0.72 & 7.47 & 283 & -0.61 & -0.54 & -0.64 & -0.66 & -0.77 & 1.40 & -0.57 & -0.23 & -0.37 & -0.33 & -0.11 & -0.40 \\
\hline $33-41$ & 8.63 & 0.06 & 4.42 & 3.13 & 0.68 & 0.01 & 0.27 & 0.02 & 30.28 & 0.64 & 5.33 & 252 & -0.50 & -0.53 & -0.52 & -0.50 & -0.67 & -0.84 & -0.44 & -0.65 & -0.31 & -0.33 & 0.00 & -0.33 \\
\hline $51-63$ & 9.11 & 0.07 & 4.98 & 3.24 & 0.75 & 0.05 & 0.29 & 0.04 & 29.48 & 0.63 & 5.38 & 253 & -0.48 & -0.47 & -0.46 & -0.49 & -0.64 & -0.25 & -0.41 & -0.32 & -0.34 & -0.35 & -0.01 & -0.30 \\
\hline $105-112$ & 10.84 & 0.12 & 4.92 & 4.21 & 1.03 & 0.02 & 0.22 & 0.04 & 27.09 & 0.59 & 5.97 & 154 & 0.02 & 0.52 & -0.13 & 0.10 & -0.18 & -0.61 & -0.25 & -0.04 & 0.00 & 0.01 & 0.08 & -0.19 \\
\hline $137-144$ & 11.10 & 0.14 & 5.02 & 4.34 & 1.07 & 0.03 & 0.23 & 0.04 & 26.90 & 0.60 & 5.84 & 149 & 0.08 & 0.82 & -0.08 & 0.17 & -0.11 & -0.14 & -0.19 & 0.09 & 0.03 & 0.06 & 0.08 & -0.18 \\
\hline \multicolumn{25}{|c|}{ Toe-slope fracture fill } \\
\hline $80-87$ & 8.94 & 0.04 & 4.54 & 3.30 & 0.69 & 0.09 & 0.35 & 0.03 & 29.98 & 0.61 & 5.91 & 279 & -0.54 & -0.89 & -0.56 & -0.53 & -0.70 & 0.24 & -0.34 & -0.55 & -0.39 & -0.42 & 0.02 & -0.35 \\
\hline $114-140$ & 8.41 & 0.10 & 3.67 & 3.04 & 0.67 & 0.13 & 0.32 & 0.04 & 30.40 & 0.66 & 5.90 & 249 & -0.51 & -0.65 & -0.60 & -0.51 & -0.67 & 1.04 & -0.33 & -0.38 & -0.30 & -0.30 & 0.00 & -0.33 \\
\hline $144-155$ & 10.26 & 0.09 & 5.09 & 3.95 & 0.89 & 0.06 & 0.27 & 0.05 & 28.05 & 0.61 & 6.31 & 178 & -0.16 & -0.58 & -0.22 & -0.11 & -0.38 & 0.27 & -0.20 & 0.02 & -0.10 & -0.11 & 0.07 & -0.26 \\
\hline \multicolumn{25}{|c|}{ Valley floor soil } \\
\hline $3-7$ & 4.97 & 0.09 & 2.21 & 1.77 & 0.32 & 0.12 & 0.28 & 0.05 & 33.68 & 0.76 & 8.66 & 323 & -0.78 & -0.48 & -0.81 & -0.78 & -0.88 & 0.40 & -0.55 & -0.39 & -0.41 & -0.38 & -0.01 & -0.46 \\
\hline $8-12$ & 5.30 & 0.06 & 2.54 & 1.74 & 0.32 & 0.14 & 0.29 & 0.05 & 34.55 & 0.78 & 6.00 & 331 & -0.77 & -0.65 & -0.79 & -0.79 & -0.88 & 0.58 & -0.55 & -0.37 & -0.41 & -0.38 & -0.09 & -0.48 \\
\hline 23-31 & 7.86 & 0.05 & 4.02 & 2.65 & 0.54 & 0.01 & 0.30 & 0.03 & 31.76 & 0.66 & 5.32 & 268 & -0.57 & -0.62 & -0.59 & -0.60 & -0.75 & -0.89 & -0.43 & -0.61 & -0.32 & -0.35 & -0.06 & -0.41 \\
\hline $42-54$ & 9.18 & 0.07 & 4.28 & 3.00 & 0.67 & 0.01 & 0.34 & 0.03 & 29.82 & 0.60 & 5.78 & 246 & -0.46 & -0.48 & -0.53 & -0.51 & -0.67 & -0.82 & -0.28 & -0.60 & -0.31 & -0.36 & -0.09 & -0.38 \\
\hline $121-133$ & 9.96 & 0.11 & 4.46 & 3.40 & 0.78 & 0.01 & 0.31 & 0.04 & 28.77 & 0.61 & 6.20 & 226 & -0.36 & -0.03 & -0.46 & -0.40 & -0.58 & -0.77 & -0.30 & -0.29 & -0.28 & -0.29 & -0.05 & -0.33 \\
\hline Parent $^{\mathrm{a}}$ & 10.7 & 0.18 & 5.67 & 3.86 & 1.26 & 0.04 & 0.30 & 0.04 & 27.2 & 0.59 & & 155 & & & & & & & & & & & & \\
\hline
\end{tabular}

${ }^{\mathrm{a}}$ Parent bedrock values are reported in Sullivan et al. (2016). 
Table 2. Mineralogy from quantitative phase analysis using XRD.

\begin{tabular}{|c|c|c|c|c|c|c|c|c|c|}
\hline Sample type & Site & $\begin{array}{l}\text { Depth } \\
(\mathrm{cm})\end{array}$ & $\begin{array}{l}\text { Quartz } \\
\text { (wt. } \\
\% \text { ) }\end{array}$ & $\begin{array}{l}\text { Illite } \\
\text { (wt. } \\
\% \text { ) }\end{array}$ & $\begin{array}{l}\text { Chlorite }^{\mathrm{a}} \\
\text { (wt. \%) }\end{array}$ & $\begin{array}{l}\text { Vermiculite } \\
\text { (wt. \%) }\end{array}$ & $\begin{array}{l}\text { Fe-oxide } \\
\text { (wt. \%) }\end{array}$ & $\begin{array}{l}\text { Kaolinite } \\
\text { (wt. \%) }\end{array}$ & $\begin{array}{l}\text { Other } \\
\text { (wt. } \\
\% \text { ) }\end{array}$ \\
\hline \multirow[t]{2}{*}{ Soil } & Ridge top & $3-7$ & 56.6 & 35.2 & 0.5 & 2.6 & 3.4 & 0.8 & 0.9 \\
\hline & Ridge top & $30-36$ & 53.0 & 36.4 & 5.0 & 1.2 & 1.9 & 1.9 & 0.6 \\
\hline \multirow[t]{5}{*}{ Fracture fill } & Ridge top & $40-90$ & 52.5 & 39.9 & 1.3 & 1.3 & 4.5 & ND & 0.5 \\
\hline & Mid-slope & $120-126$ & 69.1 & 26.3 & 0.6 & 1.0 & 1.8 & ND & 1.2 \\
\hline & Toe-slope & $80-87$ & 58.6 & 33.0 & 2.1 & 0.9 & 1.2 & 1.1 & 3.1 \\
\hline & Toe-slope & $114-140$ & 58.1 & 33.4 & 3.1 & 1.6 & 0.2 & 3.0 & 0.6 \\
\hline & Toe-slope & $144-155$ & 44.5 & 47.5 & 1.9 & 2.5 & 1.1 & ND & 2.5 \\
\hline \multirow[t]{2}{*}{ Rock } & Ridge top & $40-44$ & 34.3 & 59.5 & 3.4 & 1.7 & 0.3 & ND & 0.8 \\
\hline & Ridge top & $100-104$ & 37.8 & 56.1 & 3.0 & 1.4 & 0.4 & ND & 1.3 \\
\hline
\end{tabular}

${ }^{\text {ac }}$ Chlorite" includes true chlorite, vermiculitized chlorite, and hydroxy-interlayered vermiculite.

$\mathrm{ND}=$ not detected; detection limit for kaolinite is $0.5 \mathrm{wt} . \%$. 


\section{FIGURE CAPTIONS}

Fig. 1. The Missed Grouse Gulch (MGG) watershed is located just $0.25 \mathrm{~km}$ north of the Shale Hills watershed in the SSHCZO. Both feature similar vegetation and are developed almost entirely on Silurian Rose Hill Formation shale. Pits were excavated along a north planar slope catena that included sites at the ridge top (RT), mid-slope (MS), toe-slope (TS), and valley floor (VF).

Fig. 2. The Missed Grouse Gulch ridge top (A), mid-slope (B), toe-slope (C), and valley floor (D) excavation sites. The boundaries between the augerable regolith and weathered rock are delineated with dashed yellows line for all the pits except for the valley floor where we did not reach bedrock. An example of a large vertical facture in the bedrock is shown in the ridge top pit (see red asterisk in A). Tree roots were found only in shale fractures that contained sediment (EG). SEM images of the roots embedded in fill found on the surfaces of shale fractures show the rooting environment within bedrock $(\mathrm{H}-\mathrm{J})$.

Fig. 3. (A) Soil horizonation (see Tables S1-S4 for more detail), (B) estimated volume of rock fractures, rooting depth and distribution as (C) root length density (RLD) from cores in the augerable regolith and (D) intersections (i.e., cross sections) mapped with photographs, and (E)

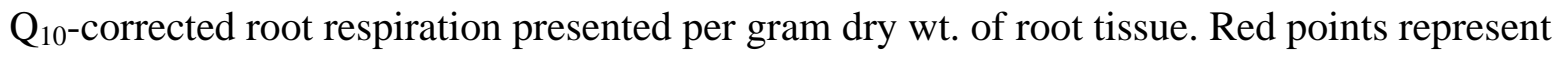
samples collected from large vertical fractures (see Fig. 2A for an example at the ridge top site) and the red lines across the point indicate the total depth range of the samples. The dashed 
yellow lines across the profiles indicate the interfaces between the augerable regolith and weathered rock.

Fig. 4. (A) Soil horizonation (see Tables S1-S4 for more detail), (B) $\mathrm{pO}_{2}$, (C) $\mathrm{pCO}_{2}$, (D) total C, (E) extractable DOC, and $(\mathrm{F})$ potential $\mathrm{C}$ mineralization. The $\mathrm{pO}_{2}$ data were collected during a single sampling event 10 days prior to digging the pits, while $\mathrm{pCO}_{2}$ data were collected 13 times over the monitoring period and the variability of $\mathrm{pCO}_{2}$ is indicated (see Fig. $\mathrm{S} 1$ for $\mathrm{pCO}_{2}$ contour plots). Red points represent samples collected from large vertical fractures and the red lines across the point indicate the total depth range of the samples. The dashed yellow lines across the profiles indicate the interfaces between the augerable regolith and weathered rock.

Fig. 5. (A) Soil horizonation (see Tables S1-S4 for more detail), (B) total N, (C) extractable $\mathrm{NO}_{3}{ }^{-}$ $-\mathrm{N}$ concentration, (D) potential net rate of $\mathrm{NO}_{3}{ }^{-}-\mathrm{N}$ accumulation, (E) extractable $\mathrm{NH}_{4}{ }^{+}-\mathrm{N}$ concentration, and (F) potential net rate of $\mathrm{NH}_{4}{ }^{+}-\mathrm{N}$ accumulation. Red points represent samples collected from large vertical fractures and the red lines across the point indicate the total depth range of the samples. The dashed yellow lines across the profiles indicate the interfaces between the augerable regolith and weathered rock.

Fig. 6. (A) Soil horizonation (see Tables S1-S4 for more detail), (B) water content, (C) pH, and (D) acid neutralizing capacity (ANC) and base neutralizing capacity (BNC). The pH was measured in solutions of deionized (DI) water (black circles), $0.01 \mathrm{M} \mathrm{CaCl}_{2}$ (gray circles), and $1.0 \mathrm{M} \mathrm{KCl}$ (white circles) with a soil weight to solution volume of 1:1. The acid neutralizing capacity and base neutralizing capacity samples represent six replicate samples to $\mathrm{pH}$ endpoints 
of 3.0 (black circles), 5.5 (gray circles), and 8.2 (white circles); error bars are shown, but for most samples the error is smaller than the sample point. Red points represent samples collected from large vertical fractures and the red lines across the point indicate the total depth range of the samples. The dashed yellow lines across the profiles indicate the interfaces between the augerable regolith and weathered rock.

Fig. 7. Plots of $\tau$ versus depth for $\mathrm{Al}, \mathrm{Fe}, \mathrm{K}, \mathrm{Mg}$, and $\mathrm{Si}$ with $\mathrm{Zr}$ as the immobile element at the (A) ridge top, (B) mid-slope, (C) toe-slope, and (D) valley floor. The fractional depletion of an element with respect to $\mathrm{Zr}$ in the parent material equals the absolute value of $\tau$ (i.e., $\tau=-0.5$ implies $50 \%$ loss of the element and $\tau=0$ indicates no loss compared to parent material). These plots show that the major elements were mostly lost in the regolith, while the weathered shale is similar to the parent material (i.e., $\tau$ values are close to 0 ). The vertical lines across the points indicate the total depth range of the samples and the horizontal lines across the points indicate the uncertainties of $\tau$ values, which were estimated by propagating the uncertainty for elemental measurements of each sample and the parent material. The dashed yellow lines across the profiles indicate the interfaces between the augerable regolith and weathered rock.

Fig. 8. The $\tau$ plots of $\mathrm{K}$ (left column) and $\mathrm{Mg}$ (right column) at the ridge top, mid-slope, and toeslope using $\mathrm{Zr}$ (triangles) and $\mathrm{Al}$ (circles) as the immobile elements. Bulk soil or rock (blue shapes) and rock fracture fill (red shapes) samples are indicated. It is estimated that $68-75 \%$ of $\mathrm{K}$ and $51-63 \%$ of $\mathrm{Mg}$ are lost as particles (the gray shaded area) when comparing $\mathrm{Zr}$ and $\mathrm{Al}$ as immobile elements. The inferred $\tau_{\mathrm{Zr}}$ for fracture fill (gray triangles) was calculated by assuming that $50 \%$ of the particles were translocated from the overlying soil layer. The vertical lines across 
the points indicate the total depth range of the samples and the horizontal lines across the points indicate the uncertainties of $\tau$ values, which were estimated by propagating the uncertainty in the elemental measurements of each sample and the uncertainty of the parent. The dashed yellow lines across the profiles indicate the interfaces between the augerable regolith and weathered rock.

Fig. 9. Photomicrographs of weathered rock from $35 \mathrm{~cm}$ below the surface at the ridge top in plane-polarized light and cross-polarized light. The images show a vertical section through the weathered rock (wr). (A) A plane-polarized light image showing hypocoatings (hc) in the weathered rock. (B) A plane-polarized light image showing a cross-section through a root with a reddish brown root sheath along the exterior. The ridge top weathered rock sample had a discontinuous clay/silt infilling (si) that occurred within a $\sim 500 \mu \mathrm{m}$-wide fracture (planar void; pv; inferred to be a fracture). (C) Higher magnification image of the root (rt) from (B) in planepolarized light. (D) A plane-polarized light image showing a fracture with clay/silt infilling and opaque coatings (oc) embedded in weathered rock. The clay/silt infilling surrounds an organic matter (om) fragment and circular void. The opaque coatings may be composed of humus, shortrange order minerals, sesquioxides, or a combination of those materials. Ferruginous coatings (fc) with high birefringence in cross-polarized light were also present. (E) and (F) are planepolarized light and cross-polarized light images, respectively, of weathered rock and a fracture with several of the features shown in previous images. The cross-polarized light image (F) shows a crescent-striated birefringent fabric (cs) suggesting that some of the clay is aligned along a preferred orientation (Stoops, 2003). In this case, it is parallel with the fracture. The crescent- 
striated birefringent fabric was discontinuous. The clay/silt infilling more commonly had a speckled birefringent fabric that was not consistent with aligned clay particles.

Fig. 10. (A) Porosity determined by neutron scattering. Results demonstrate that rock fragments in contact with roots (blue squares) had indistinguishable porosity from those which were not in contact with roots (red triangles) and the bulk regolith (tan circles). The porosities for these samples were higher than unweathered shale (purple diamonds). The inset shows the upper 150 $\mathrm{cm}$ in detail. (B) Bulk chip density decreases as a function of depth. 

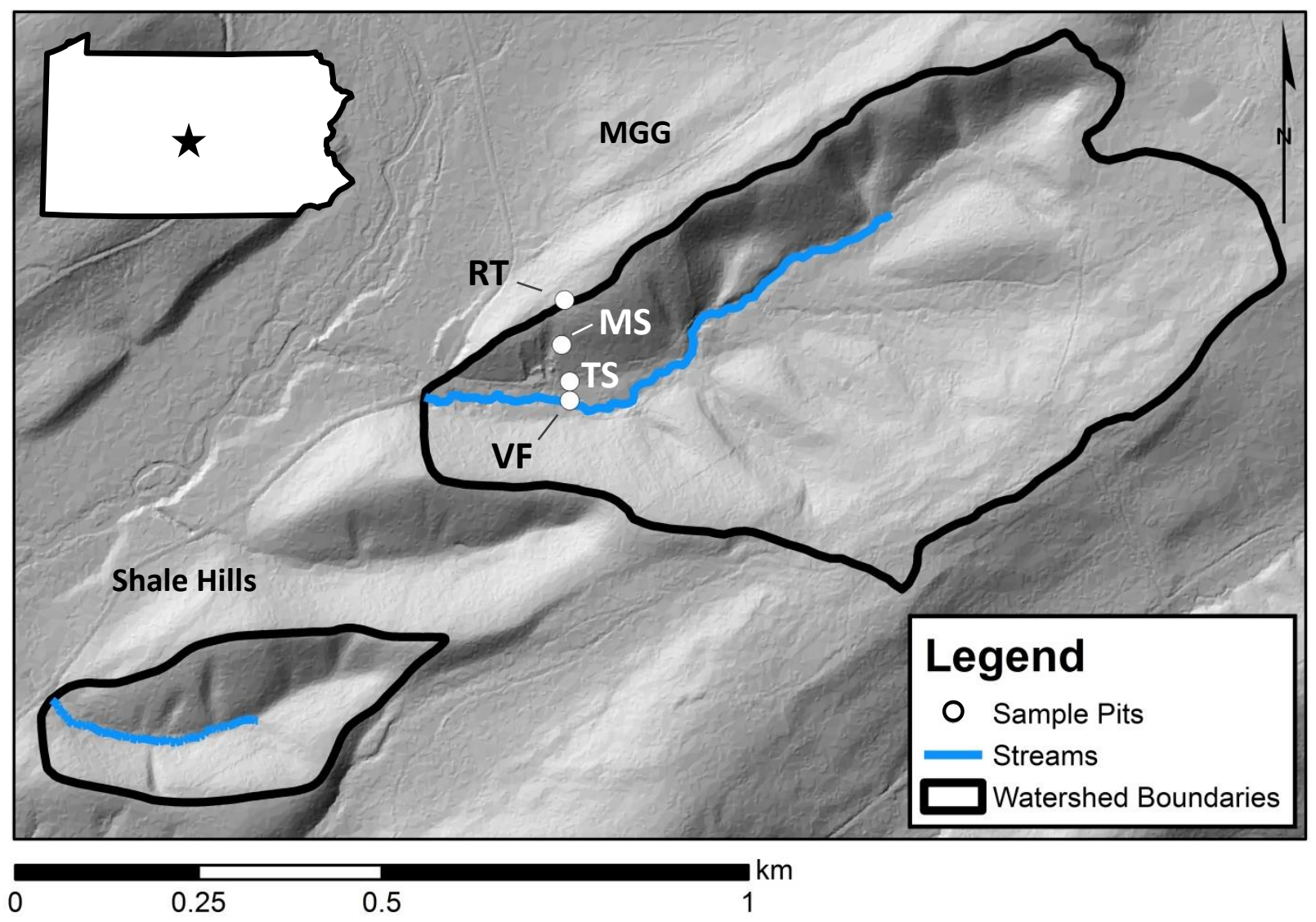


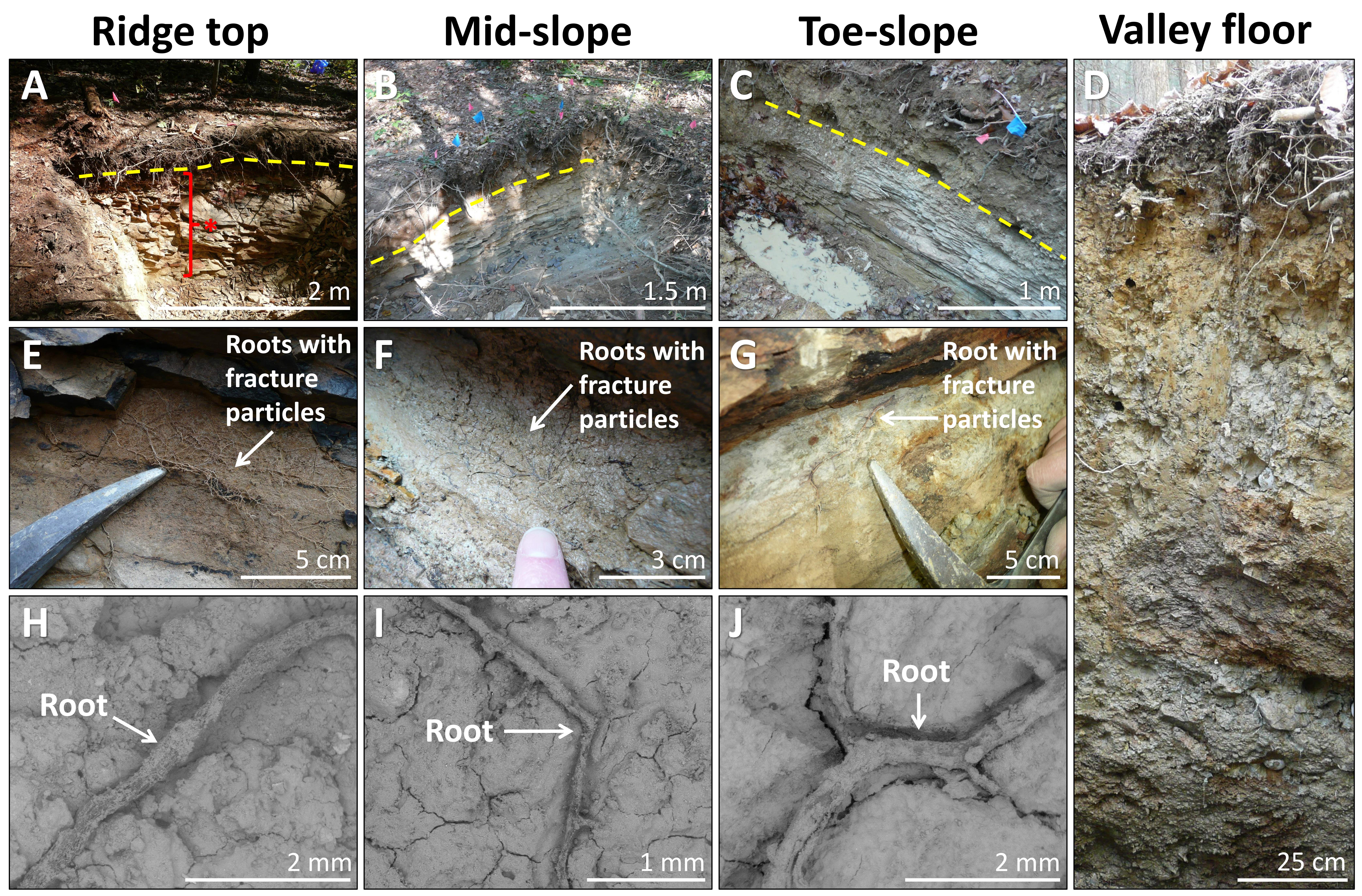


A

B $\quad$ C

D

E
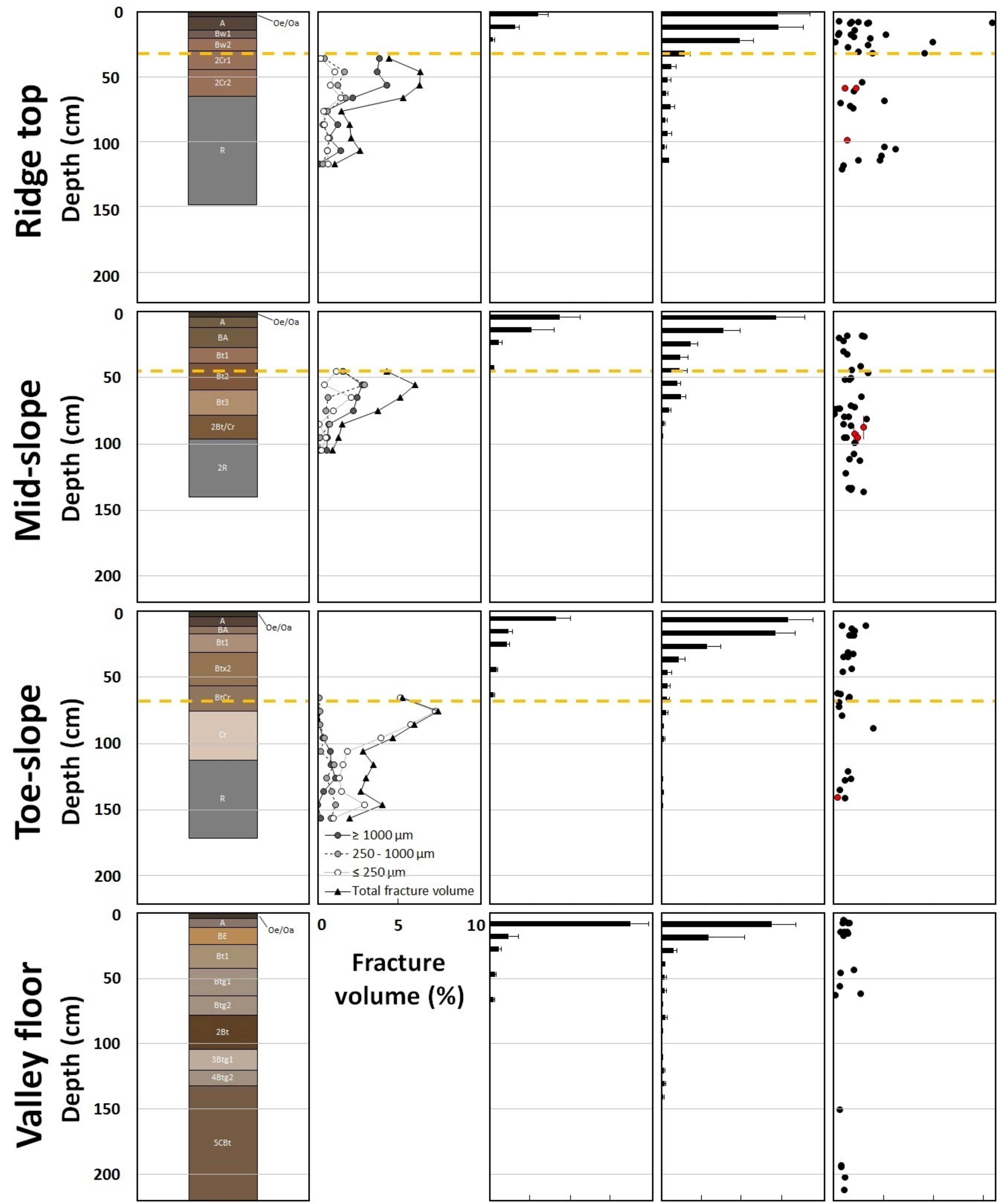

Soil horizonation
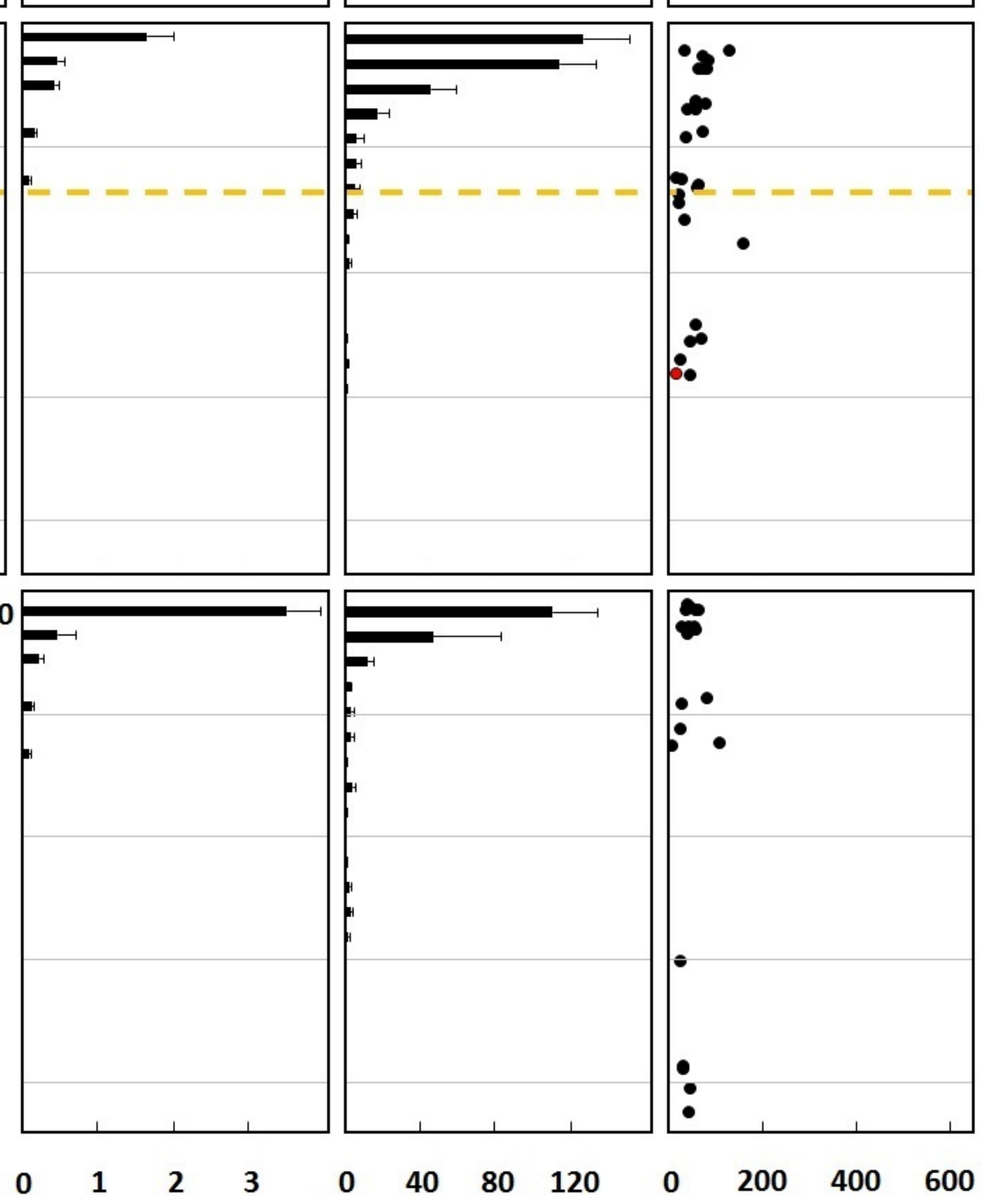
RLD Intersections Respiration $\left(\mathrm{cm} \mathrm{cm}^{-3}\right) \quad 100 \mathrm{~cm}^{-2} \quad\left(\mathrm{nmol} \mathrm{CO} \mathrm{CO}_{2}\right.$ g dry wt. ${ }^{-1} s^{-1}$ ) 


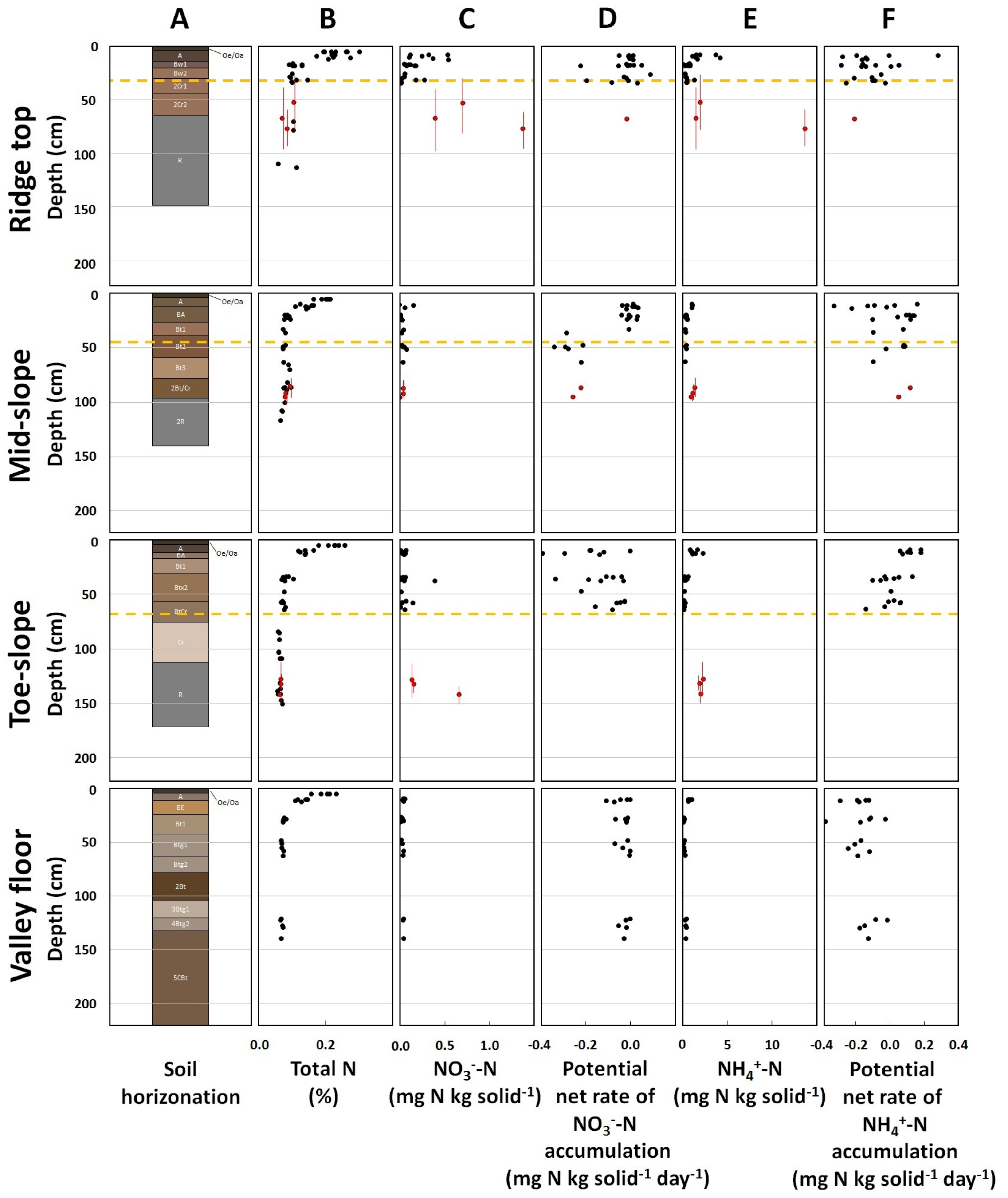


A) Ridge top

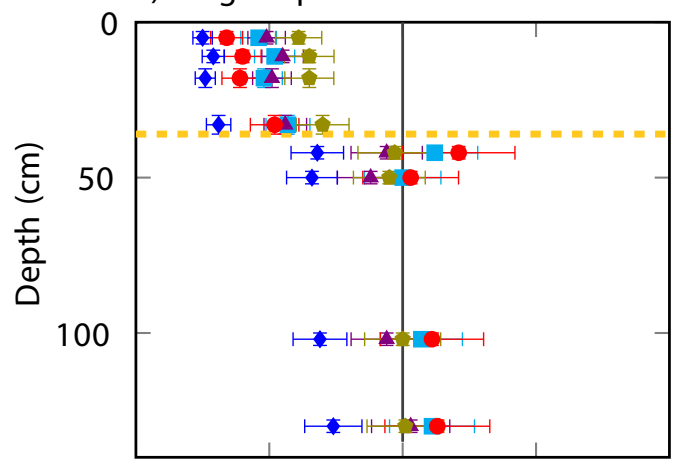

C) Toe-slope

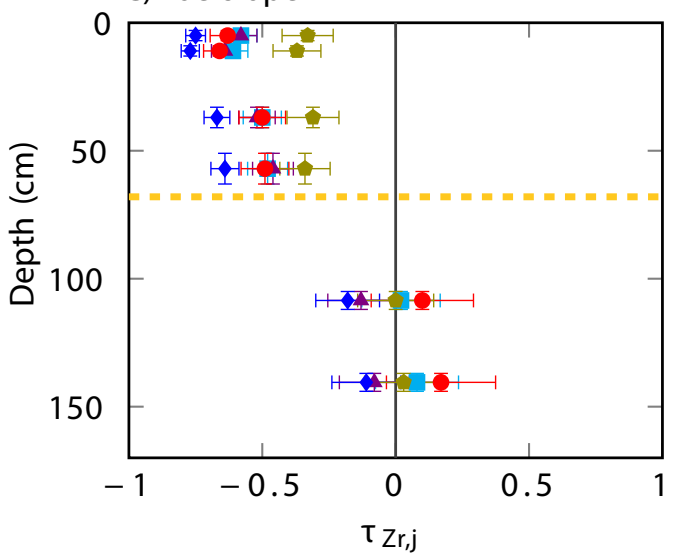

B) Mid-slope

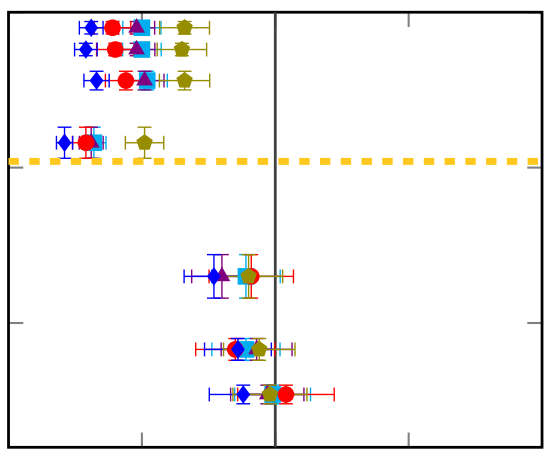

D) Valley floor

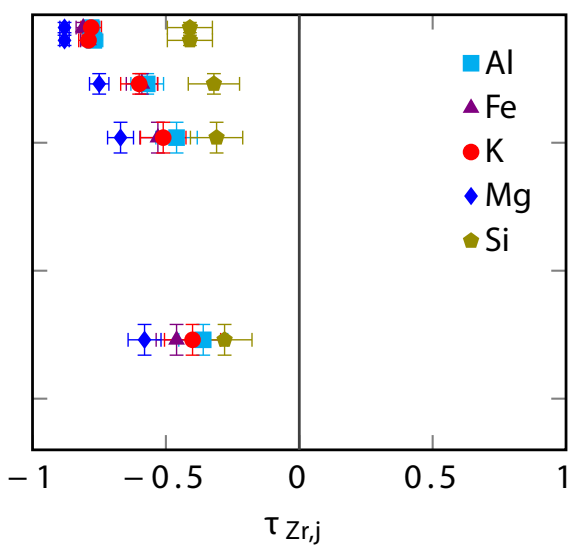




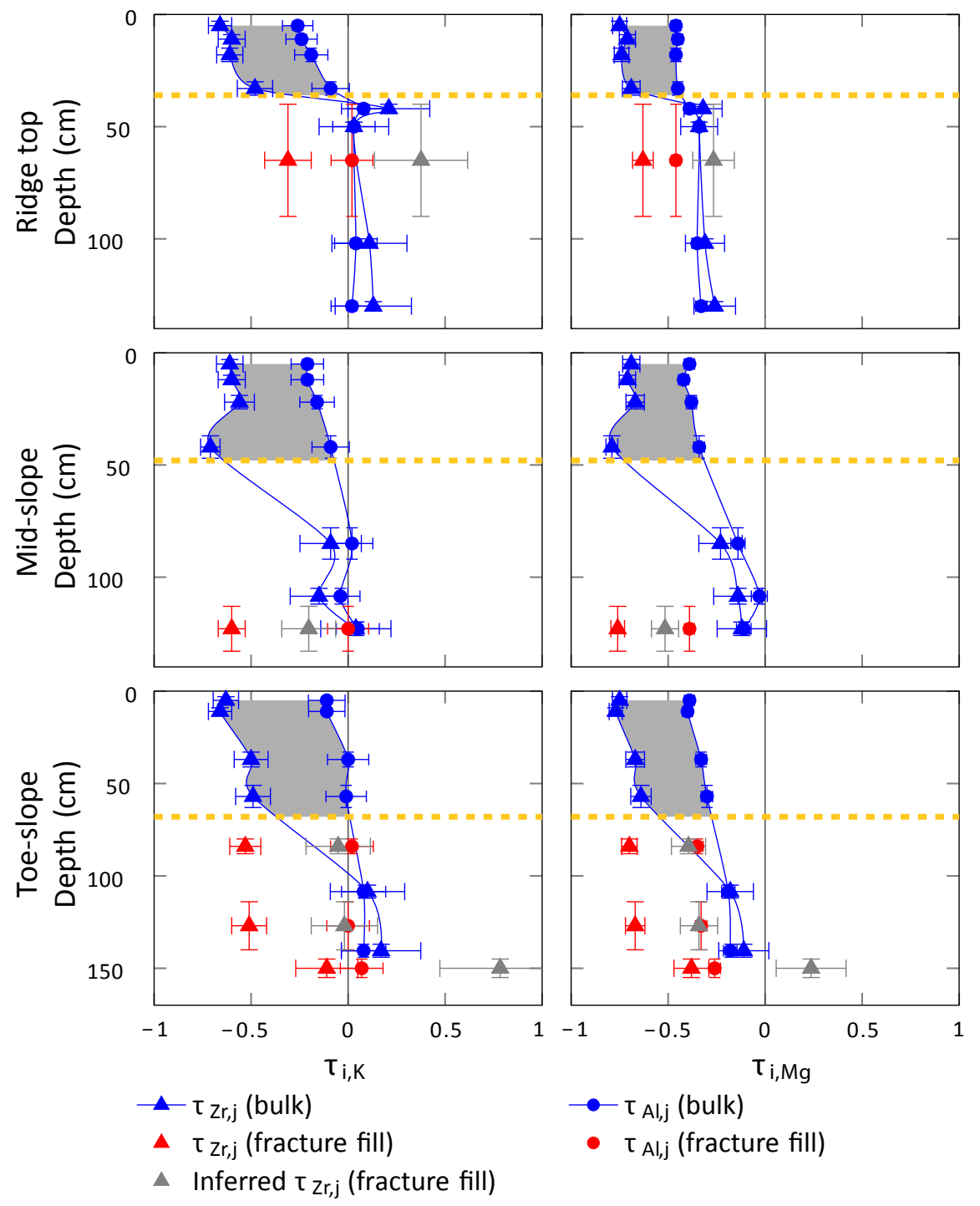




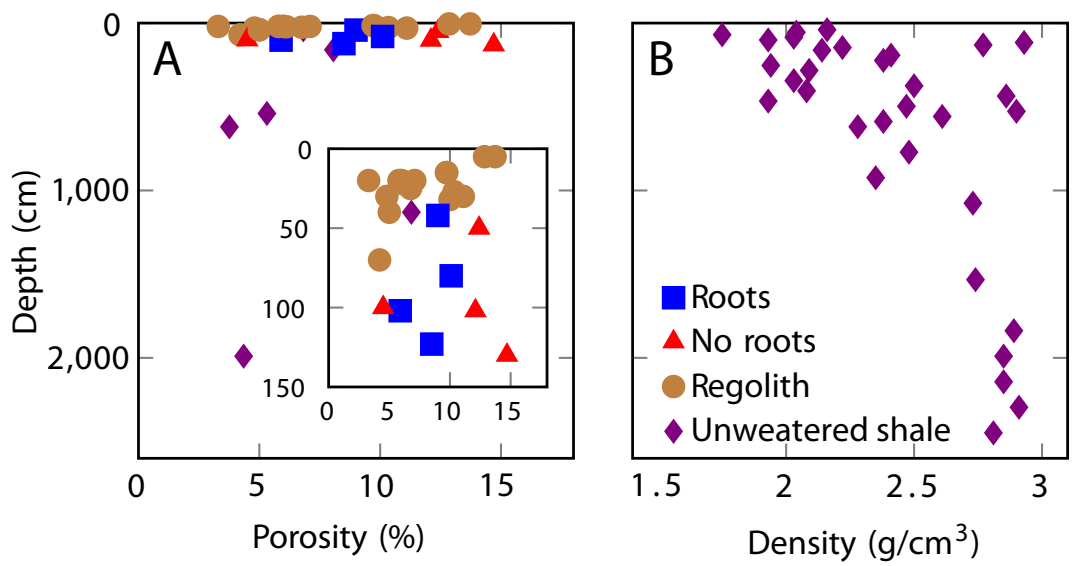


